NASA Technical Memorandum 4591

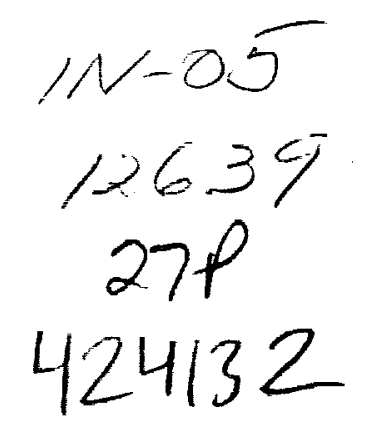

Evaluating the Dynamic

Response of In-Flight

Thrust Calculation

Techniques During

Throttle Transients

Ronald J. Ray

June 1994

(NASA-TM-4591) EVALUATING THE

N94-35241

DYNAMIC RESPONSE OF IN-FLIGHT

THRUST CALCULATION TECHNIQUES

DURING THROTILE TRANSIENTS (NASA.

Dryden Flight Research Facility)

$27 \mathrm{p}$

H1/05 0012639

Unclas

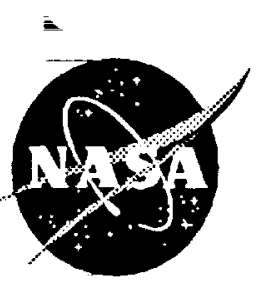


$4 .-$ 
NASA Technical Memorandum 4591

\section{Evaluating the Dynamic Response of In-Flight Thrust Calculation Techniques During Throttle Transients}

Ronald J. Ray

Dryden Flight Research Center

Edwards, California

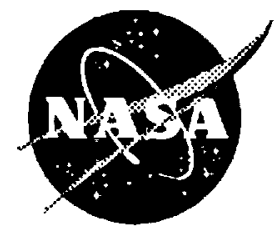

National Aeronautics and Space Administration Office of Management Scientific and Technical Information Program 


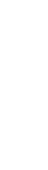




\title{
EVALUATING THE DYNAMIC RESPONSE OF IN-FLIGHT THRUST CALCULATION TECHNIQUES DURING THROTTLE TRANSIENTS
}

\author{
Ronald J. Ray* \\ NASA Dryden Flight Research Center \\ Edwards, California
}

\begin{abstract}
New flight test maneuvers and analysis techniques for evaluating the dynamic response of in-flight thrust models during throttle transients have been developed and validated. The approach is based on the aircraft and engine performance relationship between thrust and drag. Two flight test maneuvers, a throttle step and a throttle frequency sweep, were developed and used in the study. Graphical analysis techniques, including a frequency domain analysis method, were also developed and evaluated. They provide quantitative and qualitative results. Four thrust calculation methods were used to demonstrate and validate the test technique. Flight test applications on two high-performance aircraft confirmed the test methods as valid and accurate. These maneuvers and analysis techniques were easy to implement and use. Flight test results indicate the analysis techniques can identify the combined effects of model error and instrumentation response limitations on the calculated thrust value. The methods developed in this report provide an accurate approach for evaluating, validating, or comparing thrust calculation methods for dynamic flight applications.
\end{abstract}

\section{Nomenclature}

$\begin{array}{ll}\text { A/B } & \text { afterburner } \\ A J & \text { nozzle throat area, in } \\ \text { AP } & \text { area pressure (thrust correlation method) } \\ A x w & \begin{array}{l}\text { aircraft acceleration along its flightpath, } \mathrm{ft} / \mathrm{sec}^{2} \\ \text { azw }\end{array} \\ \begin{array}{c}\text { aircraft normal acceleration relative to its } \\ \text { flightpath, } \mathrm{f} / \mathrm{sec}^{2}\end{array} \\ \text { no } & \begin{array}{l}\text { nozzle throat area, in }{ }^{2} \text { or } \mathrm{ft}^{2} \\ C_{D}\end{array} \\ \text { vehicle drag coefficient }\end{array}$

Aerospace Engineer.

Copyright $\odot 1994$ by the American Institute of Aeronautics and Astronautics, Inc. No copyright is assented in the United States under Title 17, U.S. Code. The U.S. Govemment has a royalty-free license to exercise all rights under the copyright claimed herein for Governmental purposes. All other rights are reserved by the copyright owner.

\begin{tabular}{|c|c|}
\hline$C I V V$ & compressor variable guide vane, deg \\
\hline$D$ & vehicle total drag, $\mathrm{lb}$ \\
\hline$F_{e x}$ & excess thrust, $l b$ \\
\hline$E G T$ & exhaust gas temperature, ${ }^{\circ} \mathrm{C}$ \\
\hline EMD & engine model derivative \\
\hline EPR & engine pressure ratio \\
\hline$g$ & acceleration caused by gravity \\
\hline$F G$ & gross thrust, lb \\
\hline$F N$ & net thrust, lb \\
\hline FNP & net propulsive force, $l b$ \\
\hline$F N P_{\text {error }}$ & enror in net propulsive force term, $\mathrm{lb}$ \\
\hline$F_{\text {noz }}$ & nozzle exterior drag, $\mathrm{lb}$ \\
\hline$F R$ & engine ram drag, lb \\
\hline$F_{\text {spil }}$ & inlet spillage drag, lb \\
\hline FTIT & fan turbine inlet temperature, ${ }^{\circ} \mathrm{F}$ \\
\hline FVG & fan variable guide vanes, deg \\
\hline HIDEC & Highly Integrated Digital Electronic Control \\
\hline$H P V G$ & high-pressure (rotor) variable guide vanes, deg \\
\hline IFT & in-flight thrust \\
\hline$L$ & lift, lb \\
\hline Mil & military power (maximum dry power) \\
\hline $\operatorname{Max}$ & maximum power \\
\hline$N Z$ & normal load factor, 8 \\
\hline$N 1$ & fan rotor speed, rpm \\
\hline N2 & compressor rotor speed, $\mathrm{rpm}$ \\
\hline$P L A$ & power lever angle, deg \\
\hline$P L F$ & power required for level flight, deg \\
\hline PSO & ambient static pressure, $\mathrm{lb} / \mathrm{in}^{2}$ \\
\hline PS2 & engine inlet static pressure, $\mathrm{lb} / \mathrm{in}^{2}$ \\
\hline PS6 & afterburner inlet static pressure, $\mathrm{lb} / \mathrm{in}^{2}$ \\
\hline PS7 & exhaust nozzle inlet static pressure, $\mathrm{lb} / \mathrm{in}^{2}$ \\
\hline PT4 & combustor pressure, $\mathrm{lb} / \mathrm{in}^{2}$ \\
\hline
\end{tabular}


PT558 turbine discharge total pressure, $\mathrm{lb} / \mathrm{in}^{2}$

PT6 afterbumer inlet total pressure, $\mathrm{lb} / \mathrm{in}^{2}$

$R C V V$ rear compressor variable vanes, deg

RTTM real-time thrust method

$S \quad$ surface reference area, $\mathrm{ft}^{2}$

SVM state variable method (or model)

TT1 inlet total temperature, ${ }^{\circ} \mathrm{R}$

TT2 engine inlet total temperature, ${ }^{\circ} \mathrm{F}$

$V \quad$ velocity, $\mathrm{ft} / \mathrm{sec}$

$W \quad$ aircraft gross weight, $\mathrm{lb}$

WACC digital engine control computed airflow, $\mathrm{lb} / \mathrm{sec}$

WFT fuel flow, $\mathrm{lb} / \mathrm{hr}$

WT

mass flow temperature (thrust correlation method)

WI inlet airflow, $\mathrm{lb} / \mathrm{sec}$

Symbols

$\begin{array}{ll}\alpha & \text { angle of attack, deg } \\ \gamma & \text { pitch angle, deg } \\ \omega & \text { frequency, rad/sec } \\ \rho & \text { density, } \mathrm{lb} / \mathrm{ft}^{3} \\ \tau & \text { thrust incidence angle, deg }\end{array}$

Subscripts

$\begin{array}{ll}L / H & \text { left-hand engine (facing forward) } \\ R / H & \text { right-hand engine (facing forward) } \\ t & \text { time, sec }\end{array}$

\section{Introduction}

This report presents a flight test technique developed for evaluating the response of thrust calculation methods during throttle transients. Emphasis is placed on developing the calculation methodology and applying the test technique. The flight test results presented in this report are intended to demonstrate the application and support the validity of the test technique. These results are not intended to discriminate between any given thrust calculation method.

A primary requirement of aircraft performance testing is an accurate measure of in-flight thrust. Various methods have been developed to calculate installed thrust indirectly from the measurements of related engine parameters. Until recently, these methods were designed and therefore limited to quasi-steady-state flight conditions at fixed throttle settings. New in-flight thrust models have recently been developed that promise unsteady flight applications and transient throtte capability. Dynamic thrust calculation methods require new approaches to in-flight evaluation and validation to assess their accuracy during dynamic conditions.

Transient in-flight thrust determination provides new opportunities for flight test evaluations. Current aircraft performance maneuvers are accomplished purposely slow to avoid violating the quasi-steady requirement. ${ }^{1}$ Thus, today's maneuvers are time consuming and restrictive in pilot technique. Improved productivity will result through better techniques inherent with the use of transient models, albeit an improved understanding of unsteady aerodynamics will also be required. ${ }^{2}$ These developments are essential requirements for the vehicle performance evaluation of highly maneuverable aircraft. The development of accurate dynamic simulation models will benefit from the inflight validation of transient thrust models. This development is particularly important in simulators used for such pilot-training tasks requiring substantial throttle usage as carrier approach and landing, formation flight, and inflight refueling. An accurate transient thrust model also provides a means for directly evaluating engine response characteristics during throttle or engine control system inputs. This ability may be a critical need for developing accurate thrust vectoring control systems.

A number of reports have been written on quasi-steadystate, in-flight thrust calculation methods. One of the more comprehensive references, In-fight Thrust Determination, by the Society of Automotive Engineers (SAE) also addresses unsteady influences on thrust determination. ${ }^{3}$ In general, SAE found that using the traditional thrust calculation methods during rapid throttle movement could lead to large errors. Such errors are predominately caused by transient thermal effects not accounted for in these steadystate models. Instrumentation accuracy and response limitations also influence the dynamic response characteristics of the calculated thrust value. Errors in the thrust model and in the input variables contribute to the accuracy of the thrust value.

To assess the validity of in-flight thrust calculation during throttle transients, the NASA Dryden Flight Research Center, Edwards, California, has developed new flight test analysis techniques based on time-dependent, aircraft and engine performance relationships. These techniques were applied and evaluated during flight testing of the X-29A Advanced Technology Demonstrator (Grumman Aerospace Corporation, Bethpage, New York) and the F-15 Highly Integrated Digital Electronic Controls (HIDEC) (McDonnell Douglas Corporation, St. Louis, Missouri) aircraft. Although both aircraft were fully equipped for inflight thrust calculation and vehicle performance determination, no special attempts were made to optimize instrumentation for the dynamic thrust response. These vehicles simply provided a convenient opportunity to apply and assess the procedures formulated in this report. 
This report presents the methodology developed for evaluating the dynamic response of in-flight thrust models during transient engine operation. Flight test maneuvers and analysis techniques are developed and applied to high-performance aircraft. Flight test results for a variety of in-flight thrust models, including those used traditionally for steady-state applications, are used to demonstrate and validate the test techniques.

\section{Methodology}

The methodology developed to evaluate the calculated thrust value during a throttle transient is based on the force balance relationship between engine net propulsive force, $F N P$, and vehicle drag, D.14 Figure 1 shows an aircraft force balance diagram. For simplification, the following assumptions were made:

1. All forces pass through the center of gravity.

2. The aircraft is in symmetrical fight (no sideslip).

3. The gross thrust, $F G$, vector has no lateral inclination.

By resolving the forces along the flightpath (wind coordinate system, $\mathrm{X}$-axis) and assuming constant mass, the following equation results:

$$
\begin{aligned}
F G \cdot \cos (\alpha+\tau) & -F R-F_{\text {spil }} \\
& -F_{\text {noz }}-D-W \cdot \sin (\gamma) \\
& =(W / g) \cdot A x w
\end{aligned}
$$

Where

$$
\begin{aligned}
g & =\begin{array}{c}
\text { acceleration caused by gravity, } \\
\text { ft/sec }
\end{array} \\
F G & =\text { gross thrust, } \mathrm{lb} \\
F R & =\text { engine ram drag, lb } \\
F_{\text {spil }} & =\text { inlet spillage drag, } \mathrm{lb} \\
F_{n o z} & =\text { nozzle exterior drag, } \mathrm{lb} \\
W & =\text { aircraft gross weight, lb } \\
D & =\text { aircraft drag, lb } \\
A x w & =\text { aircraft acceleration along its } \\
\alpha & =\text { flightpath, f } / \mathrm{sec}^{2} \\
y & =\text { angle of attack, deg } \\
\tau & =\text { thrust incidence angle, deg }
\end{aligned}
$$

The first two terms in equation (1) also define the net thrust, $F N$, along the flightpath. That is,

$$
F N=F G \cdot \cos (\alpha+\tau)-F R
$$

Net propulsive force, FNP, is defined as the summation of all the propulsion-related forces acting on the vehicle. That is,

$$
F N P=F G \cdot \cos (\alpha+\tau)-F R-F_{s p i l}-F_{n o z}
$$

The right-hand side of equation (1) defines the aircraft excess thrust term, $F_{e x}$. That is,

$$
F_{e x}=(W / g) \cdot A x w
$$

Substituting equations (3) and (4) into equation (1) yields

$$
F_{e x}=F N P-D-W \cdot \sin (\gamma)
$$

Equation (5) provides an important relationship between aircraft drag, net propulsive force, gravity component and measurable excess thrust of the vehicle along its flightpath. The gravity component is relatively small when pitch angle is small. Equation (5) also provides a useful method for determining vehicle drag from flight data. Because excess thrust depends on acceleration measurements, this approach for determining vehicle performance is commonly referred to as the "accelerometer method."

For the wings level, quasi-steady flight condition, it can be assumed that $D$ and $W \cdot \sin (\gamma)$ are constant. Assuming the flight condition remains constant, a perturbation in net propulsive force, $\triangle F N P$, will be directly comparable to a change in excess thrust. For example,

$$
\Delta F_{e x}=\Delta F N P
$$

Likewise the time-rate-of-change in net propulsive force is equal to the time-rate-of-change in excess thrust:

$$
d F_{e x} / d t=d F N P / d t
$$

Equations (6) and (7) form the basis for the quantitative evaluation of net propulsive force during a throtle transient. Remember that the net propulsive force parameter is comprised of several engine-related forces and not just gross thrust. The excess thrust parameter is the reactionary response of all the forces acting on the vehicle along its flightpath axis and is directly measurable.

Equation (6) can be modified to account for a nonconstant drag term if required. For the case where gross thrust or net propulsive force does not pass through the center of gravity, an additional trim drag term may be required to account for the change in elevator trim position required to maintain level flightpath. 


$$
\Delta F_{e x}=\Delta F N P-\Delta D_{t r i m}
$$

Jet power effects on trim drag can be large when the thrust line passes far from the center of gravity, and the change in thrust is large.

If the aircraft changes velocity significantly during the maneuver, a time-dependent drag correction similar to equation (8) must be used to account for the resulting drag change. For example,

$$
\Delta F_{e x}=\Delta F N P-\Delta D
$$

Where $\Delta D=D_{f(t)}-D_{t=0}$

The time-dependent $\Delta D$ term is determined by first calculating the steady-state drag value, $D_{t}=0$, using equation (5). Once $D_{t}=0$ is known, the drag coefficient, $C_{D}$, can be computed using the drag equation below.

$$
D=1 / 2 \cdot \rho \cdot V^{2} \cdot S \cdot C_{D}
$$

The time-dependent drag value, $D_{f(t)}$, can then be determined directly from equation (10) using the measured velocity and assuming $C_{D}$ remains constant. Two factors must be considered when evaluating if the drag coefficient is constant: changes in trim angle of attack, $\alpha$, and compressibility effects.

Below approximately Mach 0.7 , the primary concern is a change in aircraft angle of attack that results in a change in the induced drag coefficient. For subsonic operation, the induced drag coefficient change can be determined from the change in lift coefficient as a function of angle of attack. Another factor that must be considered when testing in the transonic flight regime (above approximately Mach 0.7) is compressibility effects or changes in the wave drag. The drag coefficient can change significantly if the Mach number varies near the transonic drag rise region.

\section{Flight Test Maneuver and Analysis Techniques}

To assess the application of the time-dependent, aircraft and engine performance relationships outlined in the Methodology section, two flight test analysis techniques were developed. One technique is useful in evaluating throttle transients or steps. The other technique is useful in evaluating the response of a throttle frequency sweep. Both techniques are described in the subsections below.

\section{Throttle Step Maneuver}

The throttle step maneuver and analysis technique is based on the engine and aircraft dynamic performance relationship presented in equation (6). The maneuver is initiated by first stabilizing the aircraft at the desired flight condition such that $F_{e x}=0$. For single-engine operation, the engine is stabilized at the power required for level flight, $P L F$, throttle setting or power lever angle, $P L A$.

For aircraft with two or more engines, the test engine may be stabilized at any desired initial throttle setting provided the remaining engines can be positioned in such a way as to achieve an initial steady-state flight condition $\left(F_{e x}=0\right)$. A throttle step input or series of step inputs are then performed at various power lever angle rates, amplitudes, or both, (fig. 2(a)). The change in net thrust during the throule step must equal the change in net propulsive force. Large power lever angle inputs will cause the aircraft to accelerate and quickly change velocity, thus eventually violating the quasi-steady assumptions $(\Delta D=0)$. One way to minimize this problem is to combine a series of opposing throttle step inputs, so an advancing power lever angle step is shortly followed by a retarding power lever angle step (fig. 2(b)). Even if the quasi-steady assumption is violated, equation (9) may still be used to evaluate the dynamic thrust value.

\section{Throttle Step Analysis}

The throttle step analysis method provides a visual comparison of net propulsive force and excess thrust during the maneuver. Because of the relationship presented in equation (6), a cross-plot of net propulsive force as a function of excess thrust will ideally yield a linear relationship with a slope of one as illustrated by the dashed line in figure 3. Remember that the relationship outlined in equation (6) only holds for the short duration where aircraft drag is relatively unchanged. Errors in the calculated thrust value are depicted by the deviation in net propulsive force from the ideal $\left(\triangle F N P=\Delta F_{e x}\right)$ line. When conducting a series of power lever angle steps, the curve for excess thrust may shift during the fixed throttle portions of the maneuver because of changes in vehicle flight condition or drag. This shift is illustrated in figure 3 . The ideal lines for the opposing steps are off-set because of a change in drag (and thus excess thrust) because the velocity increases while at the maximum power (Max) condition.

\section{Throttle Frequency Sweep Maneuver}

The throttle frequency sweep method is based on the relationships developed in equations (6) and (7). This method provides quantitative information on the dynamic response of a given thrust model. An approach similar to the one used to obtain aircraft stability derivatives in flight, where the pilot inputs a range of frequencies to an aircraft surface through the stick or rudder, is used. The engineer evaluates the aircraft response as a function of input frequency. For the throttle frequency sweep 
maneuver, a range of throttle inputs at increasing or decreasing frequencies are used to excite net propulsive force which, in turn, affects excess thrust. Note that the evaluation of thrust model response relative to excess thrust does not require any knowledge about the time delay between power lever angle and net propulsive force.

The throttle frequency maneuver is initiated by stabilizing the aircraft at a power required for level flight condition as outlined in the Throttle Step Maneuver subsection. The pilot then conducts a range of constant amplitude throttle inputs at various frequencies. Figure 4 shows a typical throttle frequency sweep. The input starts at a low frequency and progresses to higher frequencies. Conversely, starting at the high frequency and proceeding to the low frequency helps to maintain stabilized flight conditions during the maneuver.

\section{Throttle Frequency Sweep Analysis}

The throttle frequency sweep analysis requires developing a frequency-based relationship between net propulsive force and excess thrust. This conversion can be done by transforming the data to a frequency domain and constructing a logarithmic plot known as a Bode plot or diagram. The fast Fourier transformation method is commonly used to convert data from a time to a frequency domain and was used in this study. The Bode plot (fig. 5) provides a direct evaluation of the frequency response characteristics (magnitude and phase shift) of a system's output relative to its input as a function of frequency, $\omega$ For the throttle frequency sweep analysis, the aircraft is considered to be the system. When the pilot provides an input to power lever angle, the engine responds by changing thrust. The aircraft responds with a measurable acceleration. Using excess thrust as the input and net propulsive force as the output facilitated obtaining the frequency response characteristics of the net propulsive force (fig. 5(a)). Excess thrust depends directly on acceleration measurements. These measurements are considered to be very accurate when compared to the net propulsive force calculation.

The key contributors to errors in the net propulsive force value are the model error and input data errors. Input data errors can be minimized through proper design of the data acquisition system and instrumentation sensors and through use of time-correlation procedures to eliminate time lags introduced through the data acquisition process. The important factor here is that the frequency response of the thrust calculation is directly influenced by the frequency response of its input parameters. Model errors are inherent in any analytical representation of a physical system. The Bode plot will show the combined effects of model and input errors on the net propulsive force calculation.
The phase value on the Bode plot (fig. 5(b)) quantifies the time shift (lag or lead) in degrees between the input and output as a function of frequency. For the ideal case where the thrust calculation is exactly in phase with the measured excess thrust value, the phase shift is $0^{\circ}$. A lag in net propulsive force is depicted by a value of less than $0^{\circ}$. The magnitude value depicts the amplitude ratio between the input and the output as a function of frequency. A decibel, $\mathrm{dB}$, is equal to $20 \log _{10}$ of the amplitude ratio. A magnitude greater than $0 \mathrm{~dB}$ represents the case where the value of the change in net propulsive force is greater than that of the change in excess thrust.

To provide a level of confidence to the frequency response results, a data coherence function is calculated to evaluate the consistency of the input and output data relationship at a given frequency. The data coherence value is one when the data exhibits its best correlation of output to input. This value will reduce when the relationship between input and output value is less consistent. If there is no dependency between the input and output value, the data coherence value is zero.

One can immediately see the quantitative value of the Bode plot for evaluating dynamic thrust calculation methods. Such plots provide a method for quantifying the dynamic thrust error and can even be used to correct the thrust value as a function of the rate of thrust change or frequency. Note that these plots provide no insight as to the magnitude of the absolute or steady-state thrust calculation error and lose their validity at very low frequencies.

\section{Engine and Aircraft Configurations}

The dynamic thrust analysis techniques were applied and evaluated during fight testing of the X-29A Advanced Technology Demonstrator and the F-15 HIDEC aircraft. Although both aircraft were fully equipped for in-flight thrust calculation and vehicle performance determination, no special attempts were made to optimize instrumentation for the dynamic thrust response. These vehicles simply provided a convenient opportunity to apply and assess the procedures formulated here.

The X-29A aircraft was equipped with an F404-GE-400 turbofan engine (General Electric Aircraft Engines, Lynn, Massachusetts) rated at $16,000 \mathrm{lb}$ thrust, sea level static. The engine instrumentation system has previously been described. ${ }^{6}$ Engine data were recorded at 25 samples/sec.

The F-15 HIDEC was equipped with an engine model derivative (EMD) version of the F100 engine, designated the PW1128 (Pratt \& Whitney, West Palm Beach, Florida). This turbofan engine was rated at $28,000 \mathrm{lb}$ thrust, sea level static. A detailed description of the engine and its instrumentation system has been given. ${ }^{\text {? }}$ 


\section{In-Flight Thrust Calculation Techniques}

Four in-flight thrust (IFT) techniques were tested using the transient thrust evaluation approaches outlined in this report: two traditional gas generator methods, one realtime technique, and one dynamic thrust model. All IFT models were developed by the respective engine manufacturers or an independent contractor for the specific engine and aircraft configurations tested. Their general purpose was to provide an accurate calculation of installed gross and net thrust for the engine throughout the flight envelope. Except for the state variable model (SVM), these thrust calculation methods were developed and intended for steady-state applications only. Their availability and widespread use in flight test applications made them convenient methods for this study.

The thrust values calculated by these models account for installation effects as a result of intemal performance of the inlet, bleed air loss, and shaft power extraction. The net propulsive force term accounts for the external forces by subtracting the inlet spillage and nozzle drag terms from net thrust (eq. (3)). External propulsive drag terms are typically less than 1 to 3 percent of the net thrust value. Propulsive drag terms depend on aircraft and engine interactions and vary with power setting and flight conditions. Normally these values are determined from wind tunnel tests using scaled models with scaled power systems. For such cases as the X-29A and F404-GE-400 configuration, these values are estimated.

\section{Manufacturers' Aerothermodynamic Thrust Models}

The most common approach for determining thrust from flight data is to consider the engine as a gas generator running at steady-state conditions with thermal and inertial equilibrium. These so-called gas generator methods tend to model the compressor, combustor, and turbine components separately to determine mass flow, pressure, and temperature conditions at the exhaust nozzle exit. Internal flowpath measurements within the gas generator are used together with mass, momentum, and energy continuity principles to calculate flow conditions at various stations within the engine and to predict overall engine performance. Procedures used to make these calculations also use correlations based on steady-state data from ground and altitude test facilities. Engine-to-engine variations are accounted for by the actual measurement values. Successful application of these steady-state correlations to flight testing has generally been limited to fixed throttle operations at stabilized or quasi-stable flight conditions.

Two engine manufacturers' IFT programs based on the gas generator method were used in this study. Both the General Electric F404 and the Pratt \& Whitney F100 EMD IFT programs use two correlation techniques for determining ideal gross thrust: area pressure, AP, and mass flow temperature, $\mathrm{WT}^{89}{ }^{8}$ The thrust value for the area pressure method strongly depends on an accurate determination of nozzle throat area, $A 8$, and nozzle pressure ratio. Nozzle pressure ratio is the ratio of nozzle throat total pressure to ambient pressure. The mass flow temperature procedure requires an accurate determination of engine mass flow rate and exhaust gas temperature for its correlation of thrust and thus requires an accurate afterburner, $\mathrm{A} / \mathrm{B}$, efficiency model. Table 1 summarizes the input measurements required for the models presented in this report. Detailed development of these gas generator methods for gross thrust calculation have been given. ${ }^{3.10}$ Gross thrust accuracies for these models are expected to be on the order of 1 to 2 percent at steady-state conditions for a nominal engine. Net propulsive force accuracies are typically 2 to 3 percent. $^{6}$

\section{Real-Time Thrust Method}

A variation of the gas generator method, the real-time thrust method (RTTM) was evaluated by NASA Dryden on the F404-GE-400 engine-equipped X-29A airplane. ${ }^{11,12}$ Gross thrust is calculated based on a one-dimensional isentropic flow analysis in the engine afterburner section and exhaust nozzle. The method requires gas-pressure measurements from three afterburner locations and a freestream stalic pressure (table 1). The afterburner pressures include the turbine exhaust total pressure and the afterburner entrance and exit static pressures. Calibration coefficients were determined during calibration of the gross thrust algorithm from data gathered on the flight test engine at the NASA Lewis Research Center (NASA Lewis), Cleveland, Ohio, and a \pm 1.80 percent uninstalled gross thrust accuracy was achieved.

Net thrust is computed from equation (2) where the ram drag term is computed from the product of inlet mass flow, $W 1$, and aircraft velocity, $V$. Inlet mass flow for the RTTM was determined by calculating the mass flow rate in the afterburner and accounting for bleed losses and fuel fow. The RTTM net thrust value was also calibrated against NASA Lewis calibration data. An overall \pm 2.74 percent uninstalled net thrust accuracy was achieved. Net propulsive force accuracy is approximately 2 to 4 percent for this method.

\section{State Variable Model}

A SVM combined with aerothermal relations was developed for the Fi00 EMD engine to calculate in-flight thrust during steady-state and dynamic engine conditions. This model consists of a simplified linear representation of the engine rather than the complex representation of each component found in nonlinear aerothermodynamic models. The SVM is based on a bivariately scheduled piecewise linear, state variable representation of the engine core 
Table 1. Thrust model measurement inputs.

\begin{tabular}{|c|c|c|c|}
\hline \multicolumn{4}{|c|}{$X-29 A$ and $F 404-G E-400^{6}$} \\
\hline \multirow[b]{2}{*}{ Parameter } & \multicolumn{3}{|c|}{ Thrust method } \\
\hline & $\begin{array}{c}\text { Area } \\
\text { pressure }\end{array}$ & $\begin{array}{l}\text { Mass flow } \\
\text { temperature }\end{array}$ & $\begin{array}{c}\text { Real-time } \\
\text { thrust }\end{array}$ \\
\hline$A 8$ & $\mathrm{XX}$ & $\overline{\mathbf{X}}$ & \\
\hline$E G T$ & & & $\mathbf{X}$ \\
\hline FVG & $\mathbf{X}$ & $\mathbf{x}$ & \\
\hline$H P V G$ & $\mathrm{x}$ & $\mathbf{X}$ & \\
\hline$M$ & $\mathbf{X}$ & $\mathbf{X X}$ & \\
\hline$N 1$ & $\mathbf{x}$ & $X$ & \\
\hline PLA & $\mathbf{X}$ & $\mathbf{X}$ & \\
\hline PSO & $\mathbf{X X}$ & $\mathbf{X}$ & $\mathbf{X}$ \\
\hline PS6 & & & $\mathbf{X}$ \\
\hline PS7 & & & $\mathbf{X X}$ \\
\hline PT558 & $\mathrm{XX}$ & $\mathbf{X}$ & $\mathrm{XX}$ \\
\hline$T T 1$ & $\mathbf{x}$ & $\mathrm{XX}$ & \\
\hline$W F T$ & $\mathbf{x}$ & $\mathrm{XX}$ & \\
\hline \multicolumn{4}{|c|}{ F-15 and F100 engine model derivatives } \\
\hline & \multicolumn{3}{|c|}{ Thrust method } \\
\hline Parameter & $\begin{array}{c}\text { Area } \\
\text { pressure }\end{array}$ & $\begin{array}{c}\text { Mass flow } \\
\text { temperature }\end{array}$ & $\begin{array}{c}\text { State } \\
\text { variable }\end{array}$ \\
\hline$\overline{A J}$ & $\bar{X}$ & $\mathrm{X}$ & $\mathrm{X}$ \\
\hline$C I W$ & $\mathrm{X}$ & $\mathbf{X}$ & $\mathrm{X}$ \\
\hline$M$ & $\mathrm{X}$ & $\mathbf{X}$ & $\mathrm{X}$ \\
\hline$N I$ & $\mathrm{X}$ & $X$ & $\mathrm{X}$ \\
\hline$N 2$ & & & $\mathrm{X}$ \\
\hline$P L A$ & $\mathrm{X}$ & $\mathrm{X}$ & $X$ \\
\hline PSO & $X$ & $X$ & $x$ \\
\hline$P S 2$ & $\mathrm{X}$ & $\mathrm{X}$ & $X$ \\
\hline$P T 4$ & & & $\mathrm{X}$ \\
\hline PT6 & $\mathrm{X}$ & $\mathrm{X}$ & $X$ \\
\hline$R C V V$ & & & $X$ \\
\hline$T T 2$ & $\mathrm{X}$ & $\mathbf{X}$ & $\mathbf{X}$ \\
\hline WACC & & & $X$ \\
\hline$W F T$ & $\mathrm{X}$ & $\mathrm{X}$ & $X$ \\
\hline TIME & & & $X$ \\
\hline
\end{tabular}

$\mathrm{X}$ - Used in thrust calculation.

$X X$ - Strongest influence on thrust calculation.

Note that influence studies have not been performed for the F-15 aircraft.

(fan to turbine). ${ }^{13}$ Augmentor and nozzle characteristics are modeled with nonlinear aerothermodynamic relations which provide input for the conventional mass flow temperature thrust calculation method.
The SVM begins by calculating a basepoint data lookup and uses a steady-state Newton-Raphson convergence algorithm on the first pass to condition input for the dynamic portion of the program. Partial derivatives generated from relationships to fuel flow and combustor pressure are used to generate the piecewise linear timedependent thrust calculation variables.

The manufacturer estimates the steady-state accuracy for net thrust to be within 2 to 3 percent and the transient accuracy to be within 5 to 10 percent based on model validation data. The SVM allows for sample data rates of up to $50 \mathrm{~Hz}$. Data acquisition was not optimized for this study. Table 1 shows the measurement input. Most of these data were sampled at $20 \mathrm{~Hz}$. Some engine parameters were sampled at $8 \mathrm{~Hz}$ because of limitations in the acquisition of output parameters from the F100 EMD digital engine control system. The low sample rates of the input data will obviously limit the response capability of the SVM.

\section{Throttle Step Results}

Throttle steps at various rates, amplitudes, and directions were performed on the F404-GE-400 engine installed in the X-29A aircraft beginning at stabilized flight conditions. Fast, medium, and slow rates were performed from power required for level flight to maximum, maximum to idle, and military to idle throttle steps. These rates varied from about $50 \mathrm{deg} / \mathrm{sec}$ for the slow rate to over $200 \mathrm{deg} / \mathrm{sec}$ for the fast rate. Actual throttle rates should be adjusted to the specific engine or thrust model being evaluated.

Thrust response was evaluated by comparing the change in net propulsive force to the change in aircraft-measured excess thrust during the transients. Figure 6 shows a sample time history of various aircraft and engine parameters obtained during a series of throtule transients. Thrust was calculated using the mass flow temperature method. Remember this method was developed and intended for quasi-steady-state applications and is primarily used here to illustrate the methodology developed in this report.

Figure 7 provides a direct comparison of net propulsive force and excess thrust for the three throttle rates and includes an ideal thrust response line (dashed) based on equation (6). Deviations from the ideal response give an indication of the errors in the net propulsive force value. The results show this thrust method tends to overpredict net propulsive force while the throttle is advanced (figs. 7(a) and 7(c)) and to underpredict it while throttling back (fig. 7(b)). This tendency can be attributed to the acceleration scheduling of fuel flow during the advancing power lever angle transient. The mass flow temperature thrust model uses measured fuel flow, fan inlet temperature, and compressor speed to calculate a temperature rise 
and mass flow rate through the engine. This calculation is accomplished using a steady-state fuel-to-air ratio and assumes an energy balance between the turbines, fan, and compressor components. Because these two assumptions do not hold true during a transient, the mass flow temperature method overestimates mass flow rate and nozzle throat temperature during throttle advancement. Meanwhile, this method underpredicts both values during throttle reductions. The tendency becomes increasingly pronounced as the throttle transient rate increases. Note that the data show closure at the end points (power required for level flight, military, maximum, and idle powers) once the engine approaches quasi-steady conditions at these settings. This finding gives confidence to the validity of the throttle step analytical approach.

Figures $7(a), 7(b)$, and $7(\mathrm{c})$ show that a difference occurs during the transition between afterbumer and dry (nonafterburner) power. The primary reason for this difference is that the thrust model uses power lever angle to select when the afterburner logic is on or off. Because this model was intended for steady-state applications, its logic does not account for augmentor transition time. This limitation is most noticeable during the maximum to military throttle power step where afterbumer fuel flow is prematurely eliminated when the power lever angle reaches military power (fig. 7(b)). As a result, an initial 4000 -lb reduction in calculated net propulsive force occurs during the fast rate transient. This reduction amounts to more than a 40-percent error from the ideal.

A similar problem can occur during throttle advancements from dry to afterburner operation if excessive noise exists on the afterbumer flow meter when no fuel flows though it. In this case, the model uses the noise as the afterburner fuel flow value. The result is an overestimation of net propulsive force. Figure 7(a) illustrates this problem during the power required for level flight to maximum power transients. For a short period while afterburner operation is being initiated, net propulsive force is influenced by the incorrect fuel flow value feeding the afterburner logic in the model. The net propulsive force value takes a sudden drop toward the ideal value as soon as minimum afterburner operation is achieved. This drop occurs because the afterburner fuel flow meter is now operating normally.

The dry power step results in figures 7(a) through 7(c) are noticeably affected by the engine acceleration and deceleration schedule but show little sensitivity to throttle rate. The slow rate idle to military power transient (fig. 7(c)), differs from the ideal net propulsive force value by up to $500 \mathrm{lb}$. The military to idle power transients (fig. 7(b)) deviate by up to $1000 \mathrm{lb}$. The value for the three rate variations is within $100 \mathrm{lb}$ of each other, indicating that the throttle may have been at a rate-limiting condition imposed by the engine control. Unfortunately because of program schedule constraints, a slower throttle rate was not performed to confirm this theory.

Figures 8(a) and 8(b) show a comparison of three thrust calculation models obtained using the medium rate throttle steps presented in figure 6 . In addition to the mass flow temperature method, the area pressure method and RTTM were evaluated and compared. Bias adjustments were made to some methods to improve their agreement at steady-state conditions and allow the ideal response line to superimpose for each method.

The area pressure method and RTTM showed improved dynamic results over the mass flow temperature method, particularly during dry power operation. This result was primarily caused by the use of fast-responding pressure values for measurement inputs and avoidance of the fuel flow measurement. The former methods also use power level angle as a logical test for afterburner indication. Results of such use show the tendency to overpredict thrust during throttle advancement from military to maximum power and to underpredict thrust while decreasing from maximum to military power. Although the area pressure method and RTTM values were not as accurate as the mass flow temperature method during steady-state comparisons, they were better at responding to the dynamic step inputs. This finding indicates that a combination of methods could yield the improved results for short maneuvers that transition from stabilized to dynamic throttle conditions.

\section{Throttle Frequency Sweep Results}

A throttle frequency sweep was performed to evaluate throule rate effects on calculated thrust. Data were obtained on the F-15 HIDEC aircraft equipped with two F100 EMD engines. The mass flow temperature and area pressure gas generator thrust methods used in this evaluation are similar in theory to those described in the Throttle Step Results section. These methods were applied by a different manufacturer than the results presented in figures 6 through 8 and use different measured parameters (table 1) on an engine with a digital electronic control system. The results must be considered independent of those presented in the Throttle Step Results section.

The throttle frequency sweep maneuver began with the aircraft stabilized at the specified flight condition. After confirming engine stabilization, the left-hand $(L / H)$ engine throttle was oscillated at a constant amplitude. The oscillation started at a frequency of approximately 0.5 $\mathrm{rad} / \mathrm{sec}$ and increased to approximately $8 \mathrm{rad} / \mathrm{sec}$ (figs. 9(a) and $9(\mathrm{~b})$ ). High friction in the throttle lever limited the 
pilot's ability to obtain smooth inputs at higher frequencies. These figures also show how some aircraft and engine parameters varied during the maneuver. Figure 9(a) reveals that the velocity of the aircraft increased over 50 $\mathrm{ft} / \mathrm{sec}$ during the maneuver and resulted in a significant change in drag $(D \neq 0)$. This velocity deviation was compensated for by making an adjustment to aircraft drag term as outline in equation (9).

An equation was developed to calculate the error in net propulsive force, $F N P_{\text {error }}$, for the test engine based on the ideal relationship presented in equation (5) and neglecting the small $W \cdot \sin \cdot(\gamma)$ term. Note the independent treatment of the two engines.

$$
F N P_{\text {error }(L / H)}=F N P_{L / H}+F N P_{R / H}-F_{e x}-D
$$

The aircraft drag and associated drag coefficient were calculated during the stabilized portion of the maneuver. A time-dependent drag term was then computed from equation (10) as a function of the vehicle drag coefficient and the velocity squared. The right-hand engine throttle was held constant during the maneuver, and its calculated thrust value varied because of the increase in velocity. This technique forces the thrust error term to neglect the steady-state error of the combined left and right thrust values while only determining the dynamic response error of net propulsive force.

Figure 10 shows the resultant error in net propulsive force for the mass flow temperature and area pressure thrust calculation methods during the frequency sweep (fig. 9(a)). The results show a noticeable difference in the dynamic response of these two methods. The dynamic error in the area pressure method for net propulsive force is much more pronounced than that of the mass flow temperature method. Closer evaluation of the data indicates that this error is primarily caused by a time lag in the calculated net propulsive force area pressure value. The error in the mass flow temperature value is much smaller than that of the area pressure value. A small phase shift is more pronounced at the higher frequencies.

The approach of using the Bode plot to evaluate the thrust response data through the frequency analysis was also applied to data from figure 9. Figure 11 illustrates the Bode plot results for the area pressure and mass flow temperature thrust methods. Because of limited stabilized data and inherent errors in the Bode plot at low frequencies, the data below $0.2 \mathrm{rad} / \mathrm{sec}$ should be dismissed. The Bode plot results confirm the error analysis results given in figure 10 . The net propulsive force mass flow temperature value stays in phase with excess thrust at frequencies up to 8 $\mathrm{rad} / \mathrm{sec}$. Whereas, the area pressure value indicates a significant phase lag $\left(-10^{\circ}\right)$ beginning at a frequency of $0.5 \mathrm{rad} / \mathrm{sec}$. Confidence in the Bode plot results is greatest when the data coherency value is one. A contributor to the phase lag in the net propulsive force area pressure results may be the engine pressure ratio (EPR) value that is input into the model. Pressure measurements are susceptible to frequency response errors if these measurements are not properly designed for dynamic applications. The EPR value shown in figure 9(b) is used as an input to calculate net propulsive force area pressure and tends to show some time lag when compared to excess thrust. Part of the problem with the EPR value, PT4/PSO, is that it is obtained from the engines digital electronic control which samples this value at a very low rate of 4 samples/sec. Such errors provide good examples of how instrumentation response error limitations can affect the calculated thrust response. Model error can also contribute to such overall results.

The magnitude results depict the amplitude difference between the input and output as a function of frequency. A magnitude greater then zero represents when the amplitude of the net propulsive force value is greater than that of the excess thrust value. The Bode plot results show that the net propulsive force mass flow temperature magnitude values are greater than zero and increase slightly with higher frequency. These values indicate a tendency for the mass flow temperature method to overshoot during the transient. This tendency is probably caused by a model error. The engine is on its acceleration and deceleration control schedule during the frequency sweep while the model assumes steady-state values. Above $8 \mathrm{rad} / \mathrm{sec}$, the net propulsive force mass flow temperature magnitude values roll off sharply below zero, indicating that the method is quickly degrading.

The area pressure method for obtaining net propulsive force results show good magnitude results up to $7 \mathrm{rad} / \mathrm{sec}$. At the higher frequency, this method begins to undershoot the excess thrust amplitude. In general for this application and maneuver, these results show that the mass flow temperature method is superior in phase shift to the area pressure method. However, this method shows no improvement in magnitude.

The SVM was evaluated using the throttle frequency sweep maneuver. Figure 12 shows the Bode plot results from this model. These data were also obtained from the maneuver presented in figure 9. Although the SVM results show improved magnitude and phase characteristics over the area pressure for net propulsive force results (fig. 11), they do not show significant improvements over mass flow temperature for net propulsive force (fig. 11(b)). The coherency value indicates reasonable phase and magnitude values were obtained up to approximately $7 \mathrm{rad} / \mathrm{sec}$. 
Again, limitations in the response of the measured values input to the SVM thrust model are a primary suspect in these results. Because the flight test analysis method does not distinguish between error sources (model or input measurements) the expected improved dynamic response of the SVM is not reflected in these results. The important result here is that the dynamic thrust analysis technique can detect limitations in the instrumentation system as well as in the model. Once identified, improvements in the instrumentation system can be made to improve the response of the thrust model.

As can be seen, the Bode plots provide a comprehensive analysis of the dynamic thrust response. The information they provide allows for a quantified comparison of thrust methods and for the effects of instrumentation system limitations. Another advantage of the Bode plot is that it can be used to correct the dynamic net propulsive force values. The quantified magnitude and phase shift errors can be applied to the calculated data to provide a more nearly accurate value of net propulsive force for an increased frequency range. The results of this example are limited to one flight condition. Additional maneuvers should be used to evaluate consistency and changes altitude, Mach number, and power level angle amplitude have on these results.

\section{Conclusions}

New flight test maneuvers and analysis techniques for evaluating the dynamic response of in-fight thrust models during throttle transients have been developed and validated. The approach is based on the aircraft and engine performance relationship between thrust and drag. Two flight test maneuvers, a throttle step and a throttle frequency sweep, were developed and used in this study. Graphical analysis techniques, including a frequency domain analysis method, were also developed and evaluated. Flight test application on two high-performance aircraft confirmed the test methods as valid and accurate. These maneuvers and analysis techniques were also found easy to implement and use. Four thrust calculation methods, including those used traditionally for steady-state applications, were used to demonstrate and validate the test technique. Flight test results indicate the analysis techniques can identify the combined effects of model error and instrumentation response limitations on the calculated thrust value.

Two flight test maneuvers, a throttle step and a throttle frequency sweep, were applied to the X-29A Advanced Technology Demonstrator and an F-15 Highly Integrated Digital Electronic Controls aircraft at the NASA Dryden Flight Research Center. Both aircraft were equipped to calculate steady-state vehicle performance. These vehicles were used to demonstrate the flight test techniques because of their availability. The flight results indicate all thrust models were affected to some degree by instrumentation limitations in frequency response. No attempt was made to minimize these errors even though the instrumentation was designed for steady-state applications. As expected, limitations were found in using the conventional (steadystate) thrust models during throttle transients, particularly during transitions to and from the afterbumer. Model and input error limitations were observed.

Flight test results proved that the throttle step maneuver and analysis technique provides a good qualitative evaluation of dynamic thrust accuracy with limited quantitative results. This techniques provides a visual comparison of the calculated dynamic thrust value deviation from the measured acceleration during a throttle transient. This very simple method requires conventional flight test measurements to implement. Flight test data show good agreement between the beginning and ending thrust values and their associated excess thrust values and give confidence to the validity of the test method.

The throttle frequency sweep maneuver was demonstrated, and the resulting flight data were plotted in the frequency domain or on a Bode plot. This technique provides a complete quantitative evaluation of the dynamic response of a thrust model. Although more complex than the throttle step method, the results from the Bode plot provide more tangible information and a means of correcting the thrust method phase lag and amplitude variation. Results of this effect confirm the flight test techniques as valid and provide a useful means for evaluating thrust model accuracy during throttle transients.

\section{References}

"Thrust and Drag: Its Prediction and Verification," Progress in Astronautics and Aeronautics, vol. 98, 1985.

${ }^{2}$ Flying Qualities Theory and Flight Test Techniques: Dynamic Parameter Analysis, USAF Test Pilot School, Aug. 1978. (Requests for this document must be referred to USAFTPS/TENC, Edwards AFB, California 93523.)

\footnotetext{
3/n-fight Thrust Determination, SAE SP-674, May 1984.
}

${ }^{4}$ Anderson, John D., Jr., Introduction to Flight: Its Engineering and History, McGraw-Hill, New York, 1978.

${ }^{5}$ Beeler, De E., Donald R. Bellman, and Edwin J. Saltzman, Flight Techniques for Determining Airplane Drag at High Mach Numbers, NACA TN 3821, 1956. 
${ }^{6}$ Ray, Ronald J., Evaluation of Various Thrust Calculation Techniques on an F404 Engine, NASA TP-3001, 1990.

${ }^{7}$ Conners, Timothy R., Thrust Stand Evaluation of Engine Performance Improvement Algorithms in an F-15 Airplane, NASA TM-104252, 1992.

8"F404-GE-400 Engine In-flight Thrust Calculation Program," G.E. program no. 83112, General Electric Co., 1983.

'F100-PW-100 In-fight Thrust Calculation User's Manual for Customer Computer Deck CCD 1088-10, Pratt \& Whitney Co., West Palm Beach, Florida, FR-6823, Jan. 1975.

${ }^{10}$ Burcham, Frank W., Jr., An Investigation of Two Variations of the Gas Generator Method To Calculate the
Thrust of the Afterburning Turbofan Engines Installed in an F-111A Airplane, NASA TN D-6297, 1971.

"Alexander, R.I. and R.J. Ray, Development and Flight Test of a Real-Time Thrust Measurement Technique on the X-29A/F404 Advanced Technology Demonstrator, NASA TM-101707, 1989.

${ }^{12}$ Ray, R.J., J.W. Hicks, and R.I. Alexander, Development of a Real-Time Aeroperformance Analysis Technique for the X-29A Advanced Technology Demonstrator, NASA TM-100432, 1988.

${ }^{13}$ Computer Simulation User's Manual for CCD 1366-00.0-PWII28 In-fight Thrust Calculation, Pratt \& Whitney Co., West Palm Beach, Florida, FR-21219, Feb. $19,1990$.

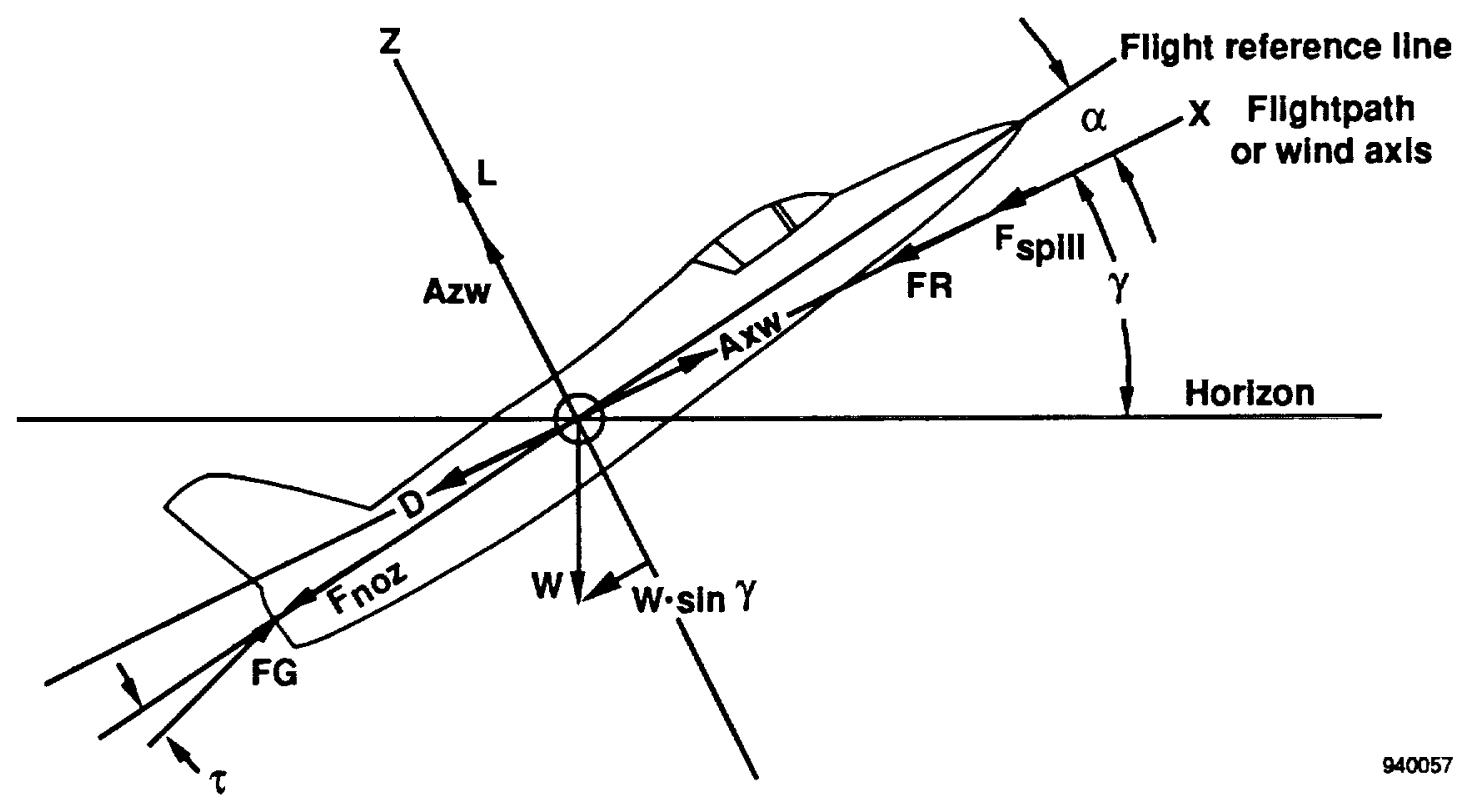

Figure 1. Aircraft force balance. 


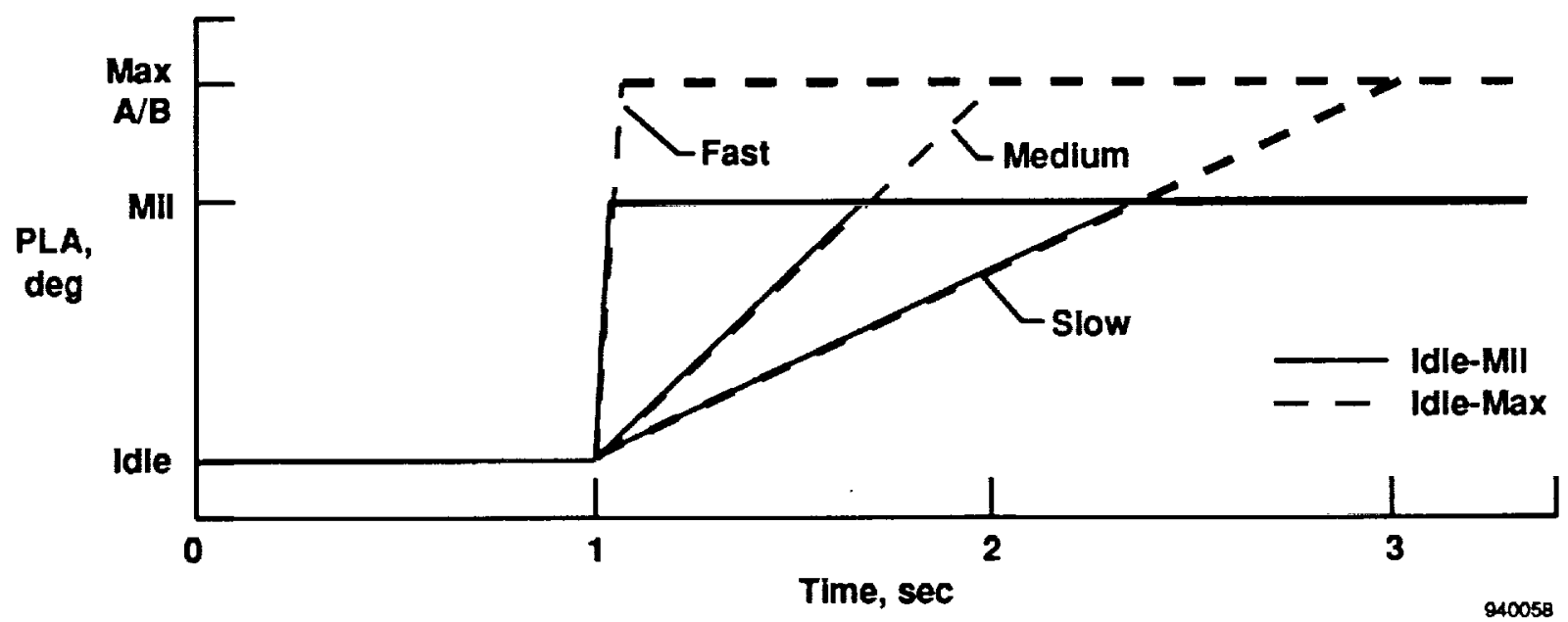

(a) Throttle transient rates and amplitutes.

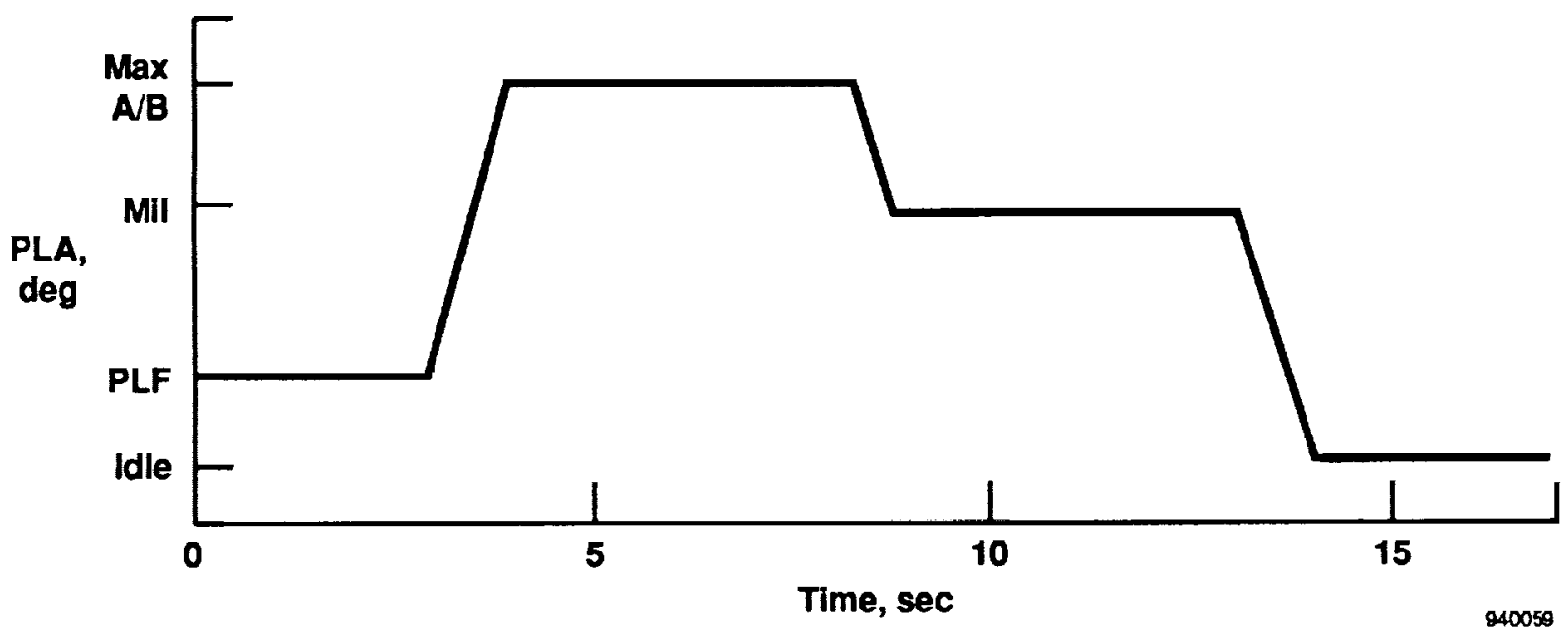

(b) Series of opposing throttle steps.

Figure 2. The throttle step inputs. 


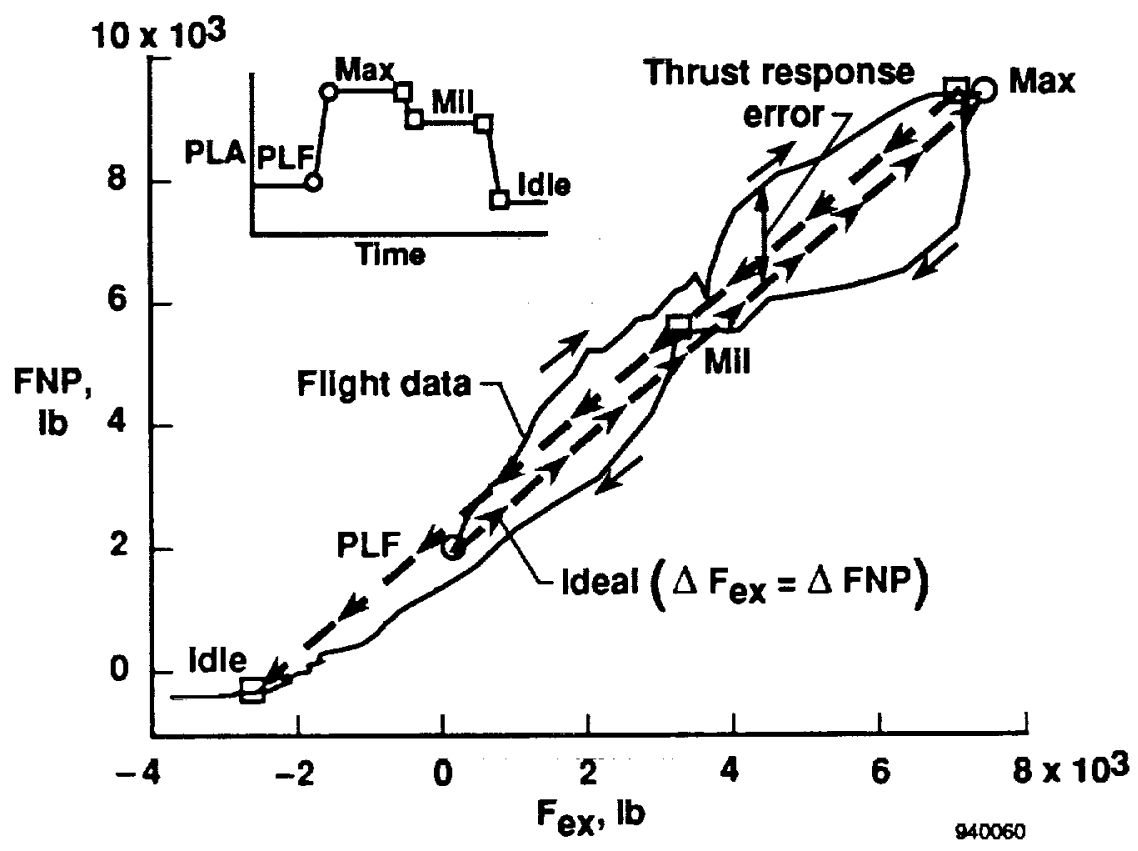

Figure 3. Throttle step analysis method. The thrust response error is depicted graphically as a deviation from the ideal.

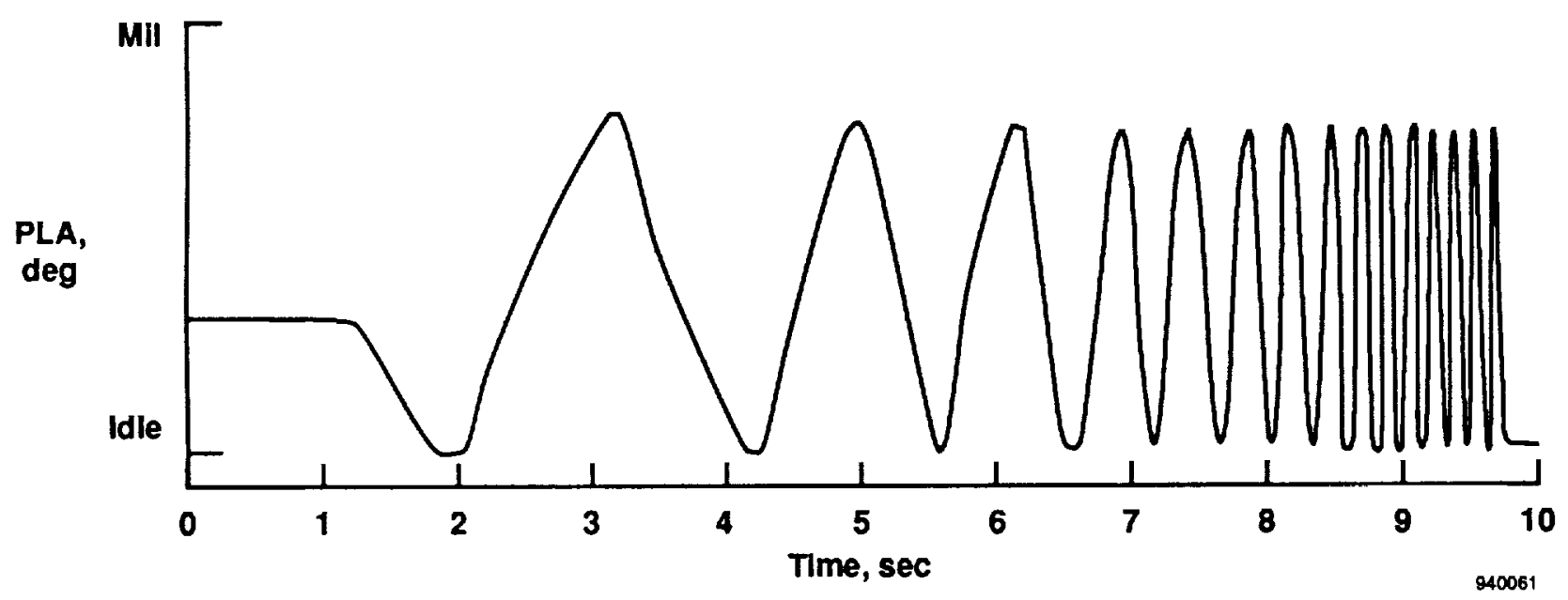

Figure 4. Typical throttle input during frequency sweep. 


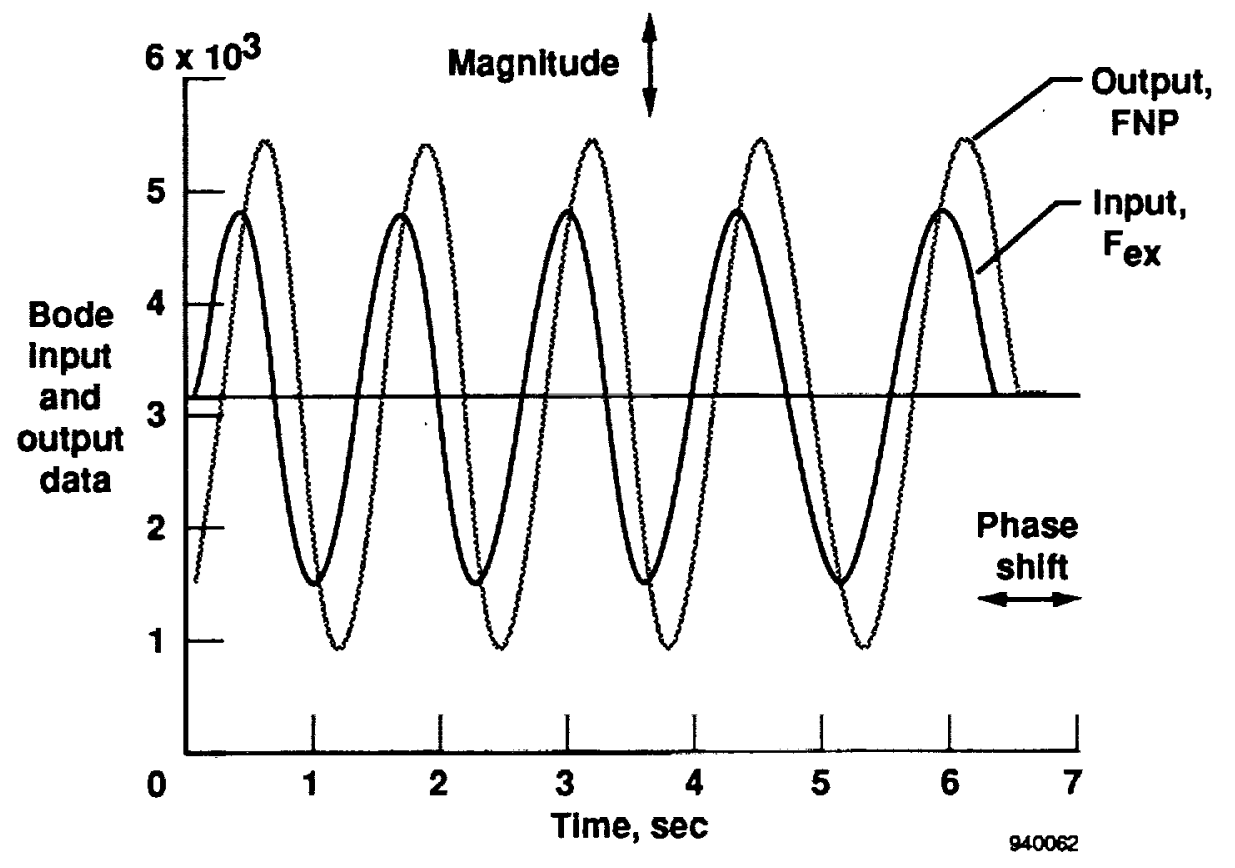

(a) Bode input and output data time histories.
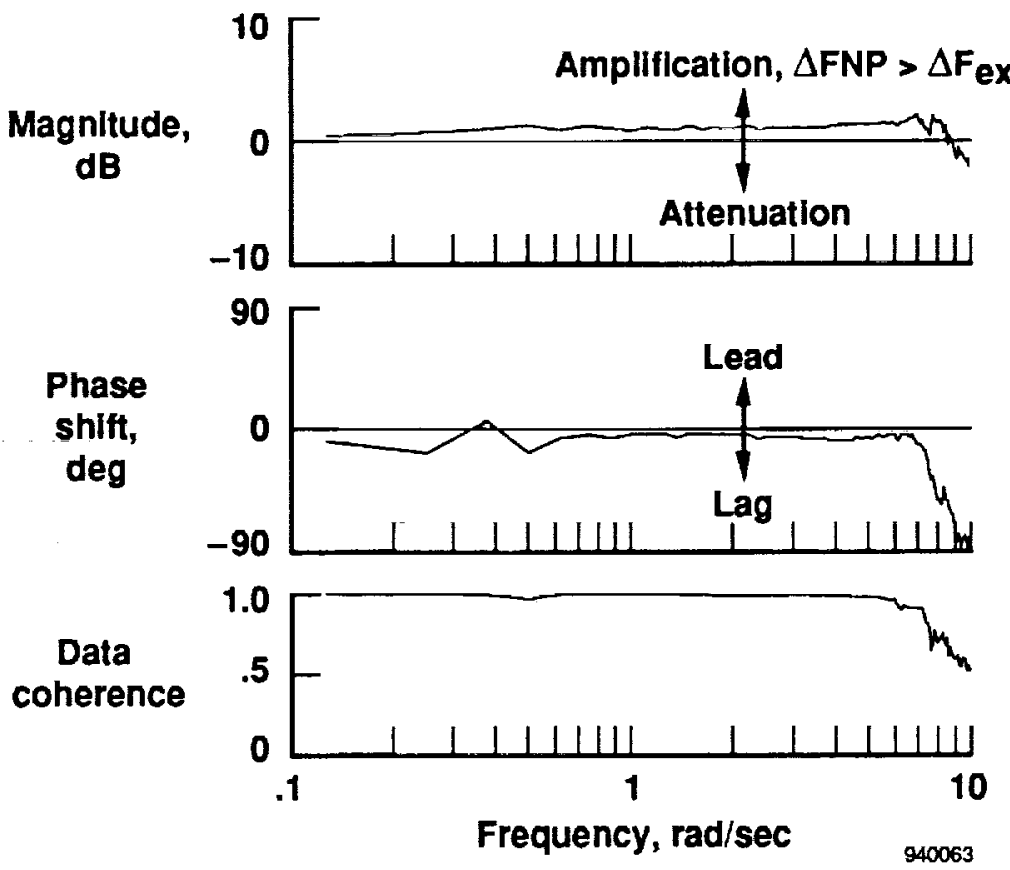

(b) Bode plot.

Figure 5. Bode frequency response. Best results for data coherence are obtained when coherence equals one. 


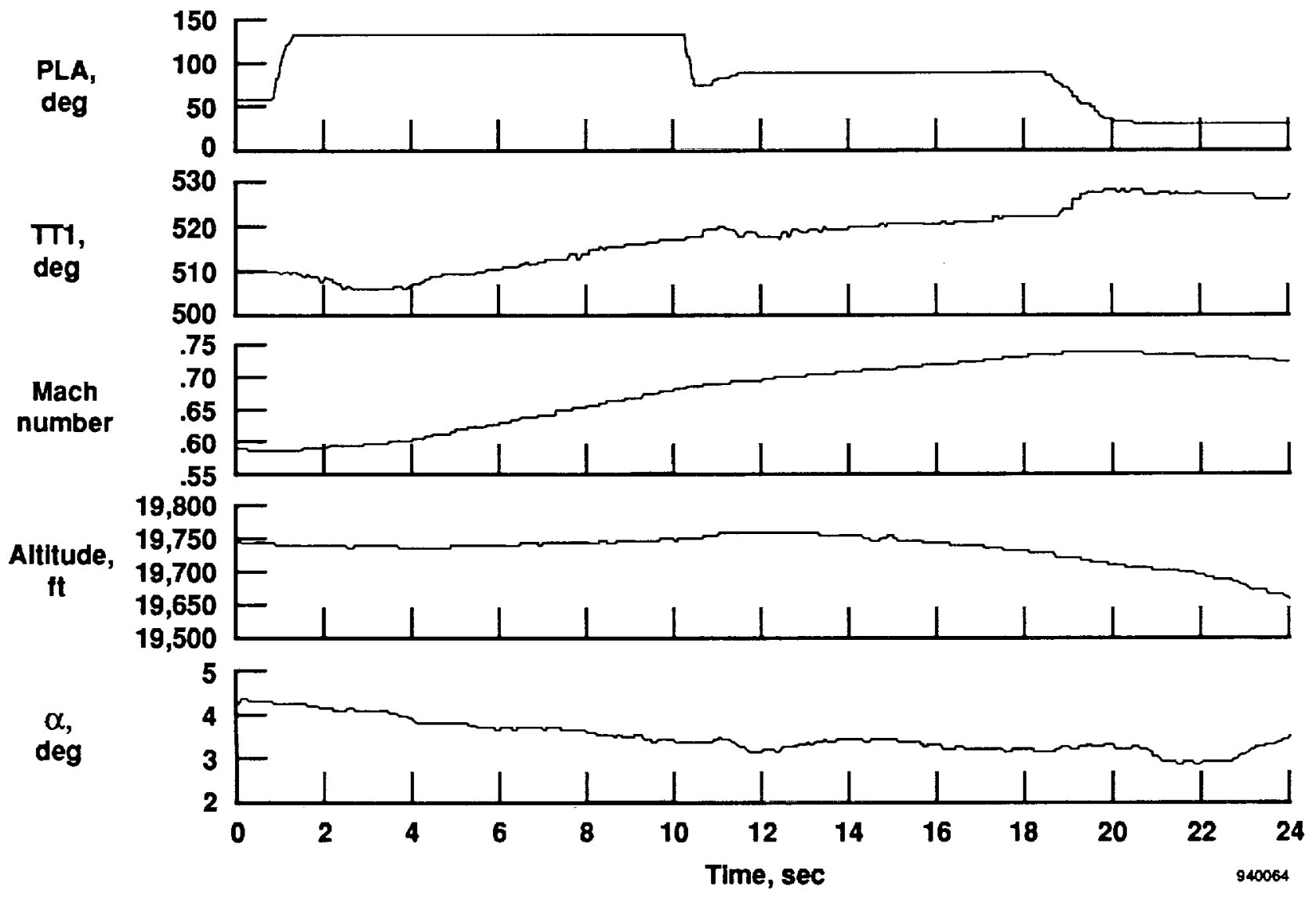

(a) Aircraft flight conditions.

Figure 6. Throttle transient time histories for an X-29A airplane with an F404-GE-400 engine. 


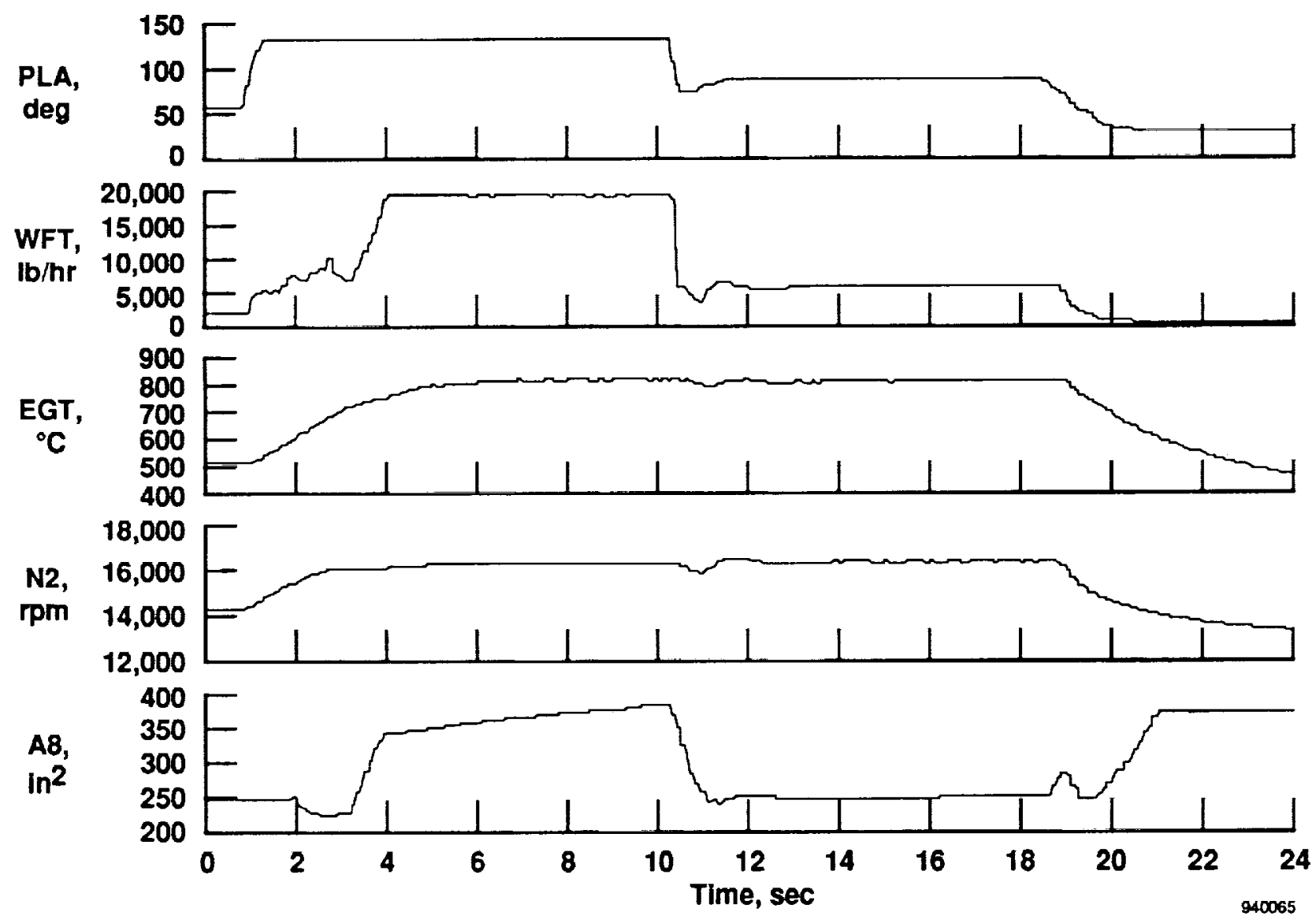

(b) Engine parameter values.

Figure 6. Continued. 

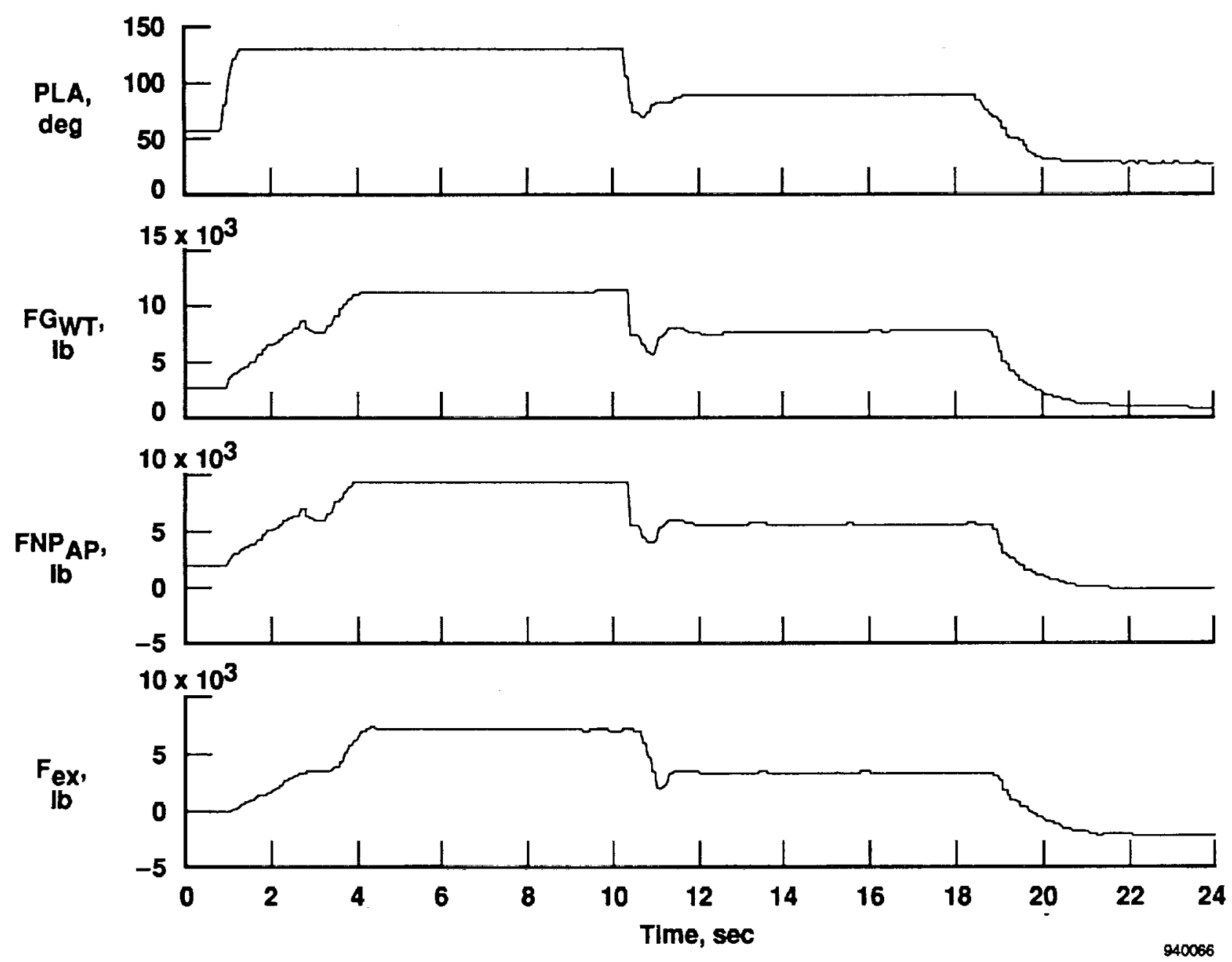

(c) Engine and aircraft performance values.

Figure 6. Concluded. 


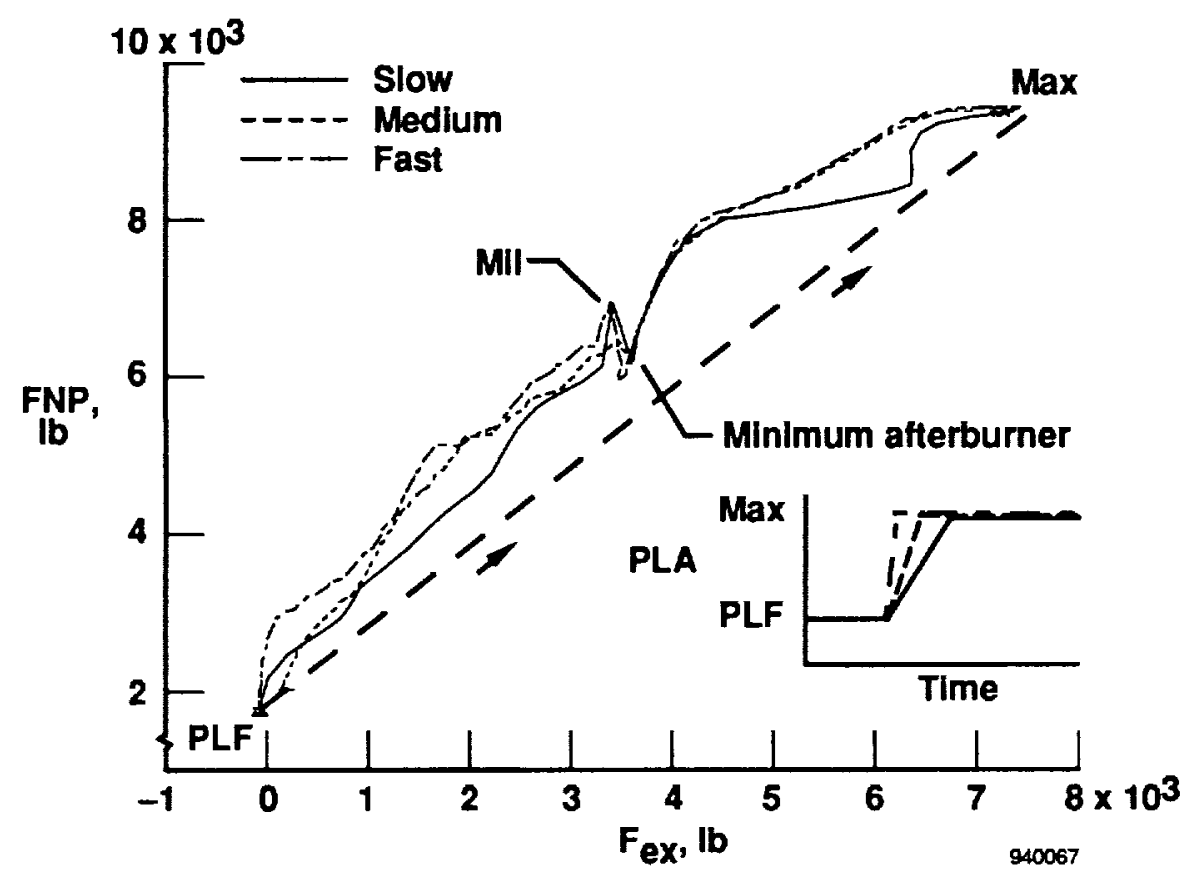

(a) Power required for level flight increasing to maximum power.

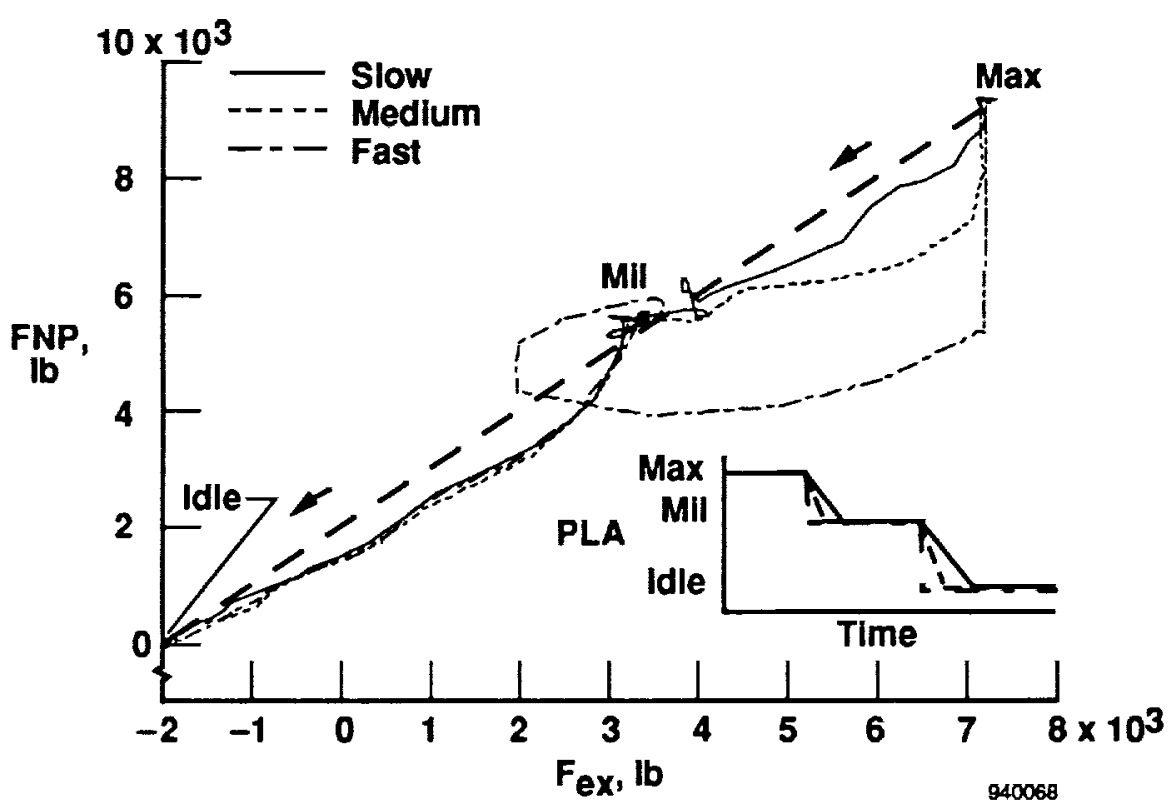

(b) Maximum to military to idle power.

Figure 7. Application of the throule step maneuver to evaluate power level angle rate effects on the dynamic response of a thrust calculation model, $F N P_{W T}$ for an X-29A aircraft, F404-GE-400 engine, at an altitude of $20,000 \mathrm{ft}$, and at Mach 0.6. 


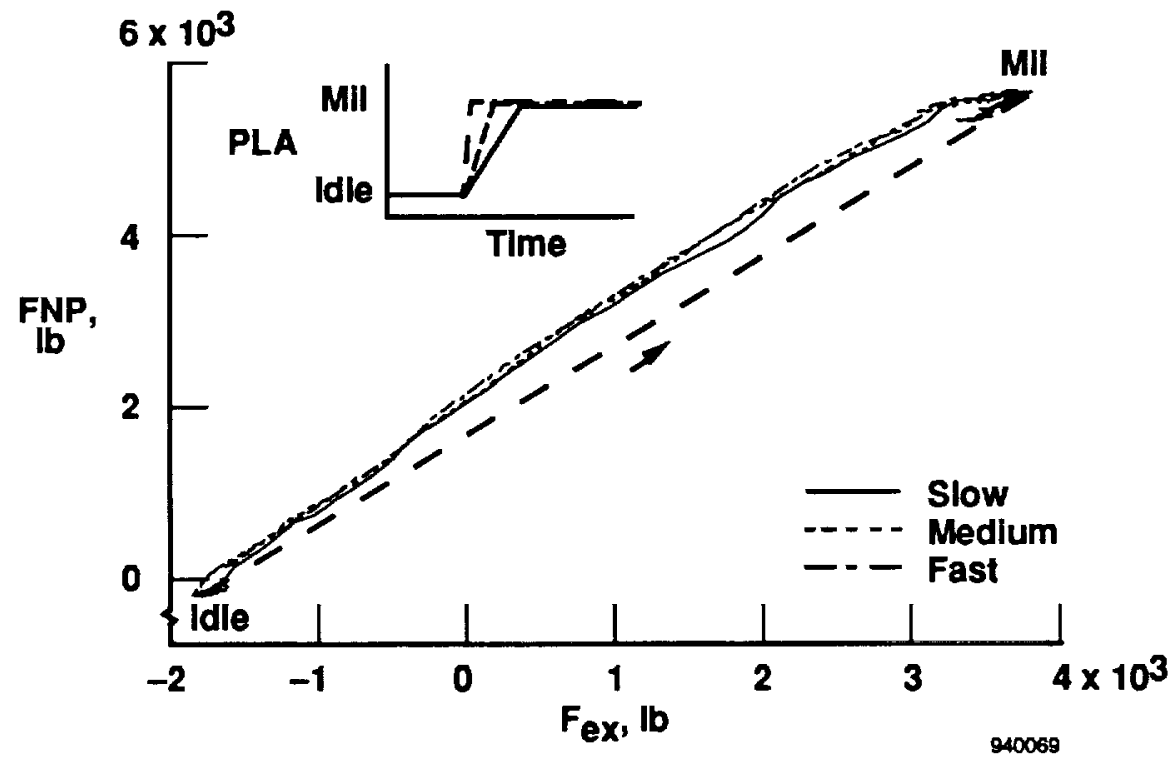

(c) Idle to military (dry power step).

Figure 7. Concluded.

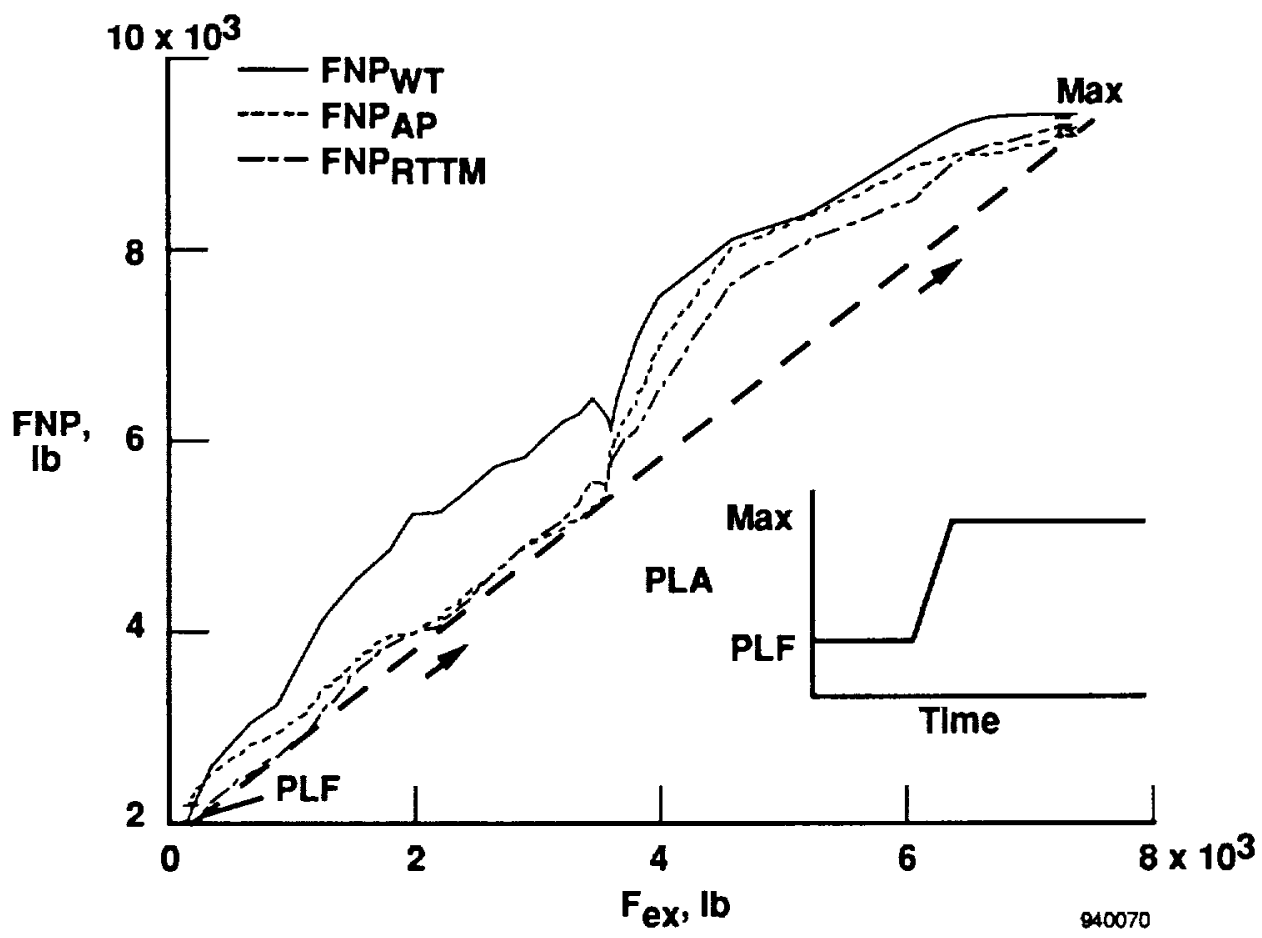

(a) Power required for level flight to maximum power.

Figure 8. The dynamic response of three thrust models during a throttle step maneuver for an X-29A aircraft, F404-GE400 engine, at an altitude of $20,000 \mathrm{ft}$, and at Mach 0.6. 


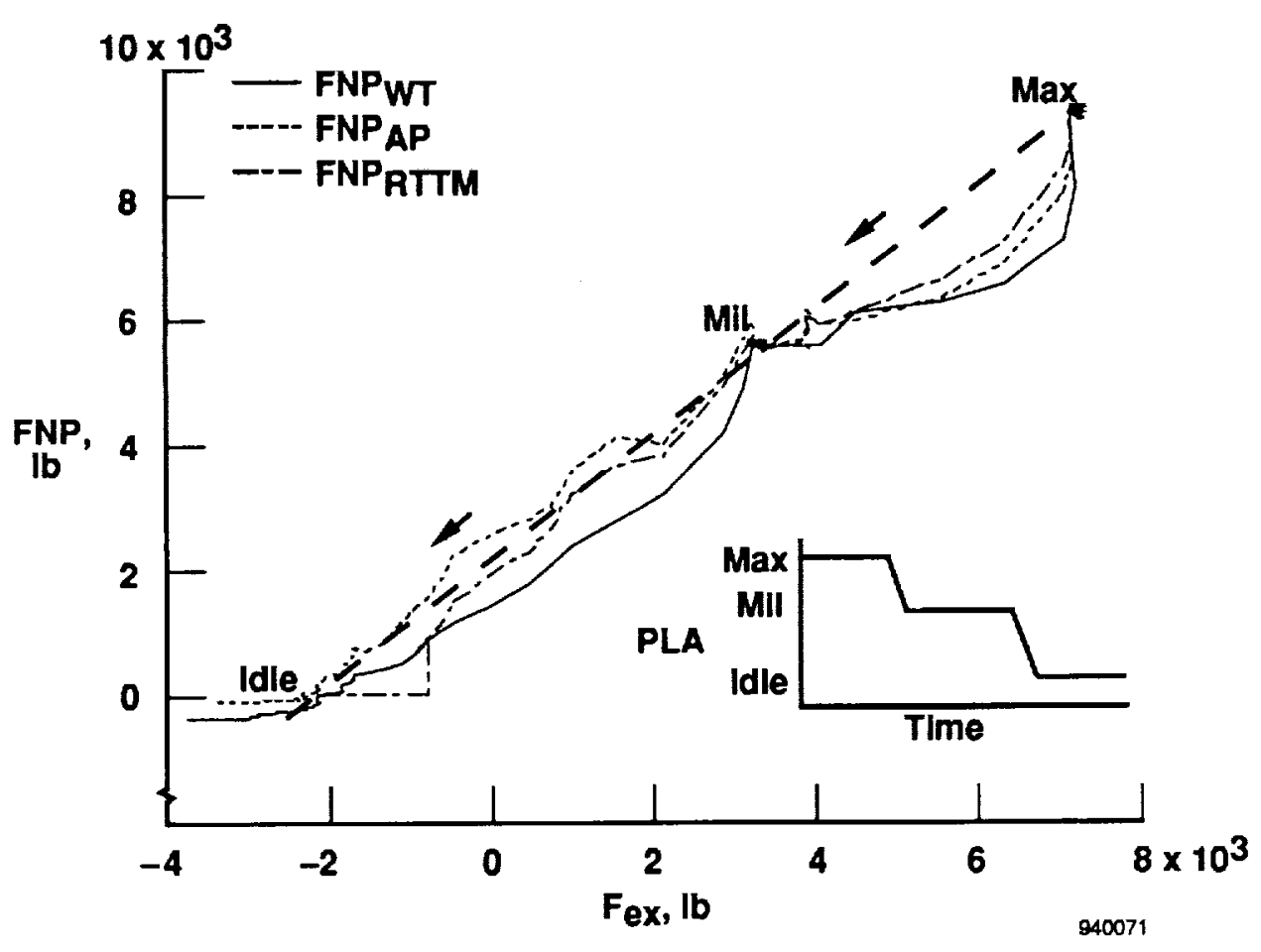

(b) Maximum to military to idle power.

Figure 8. Concluded. 

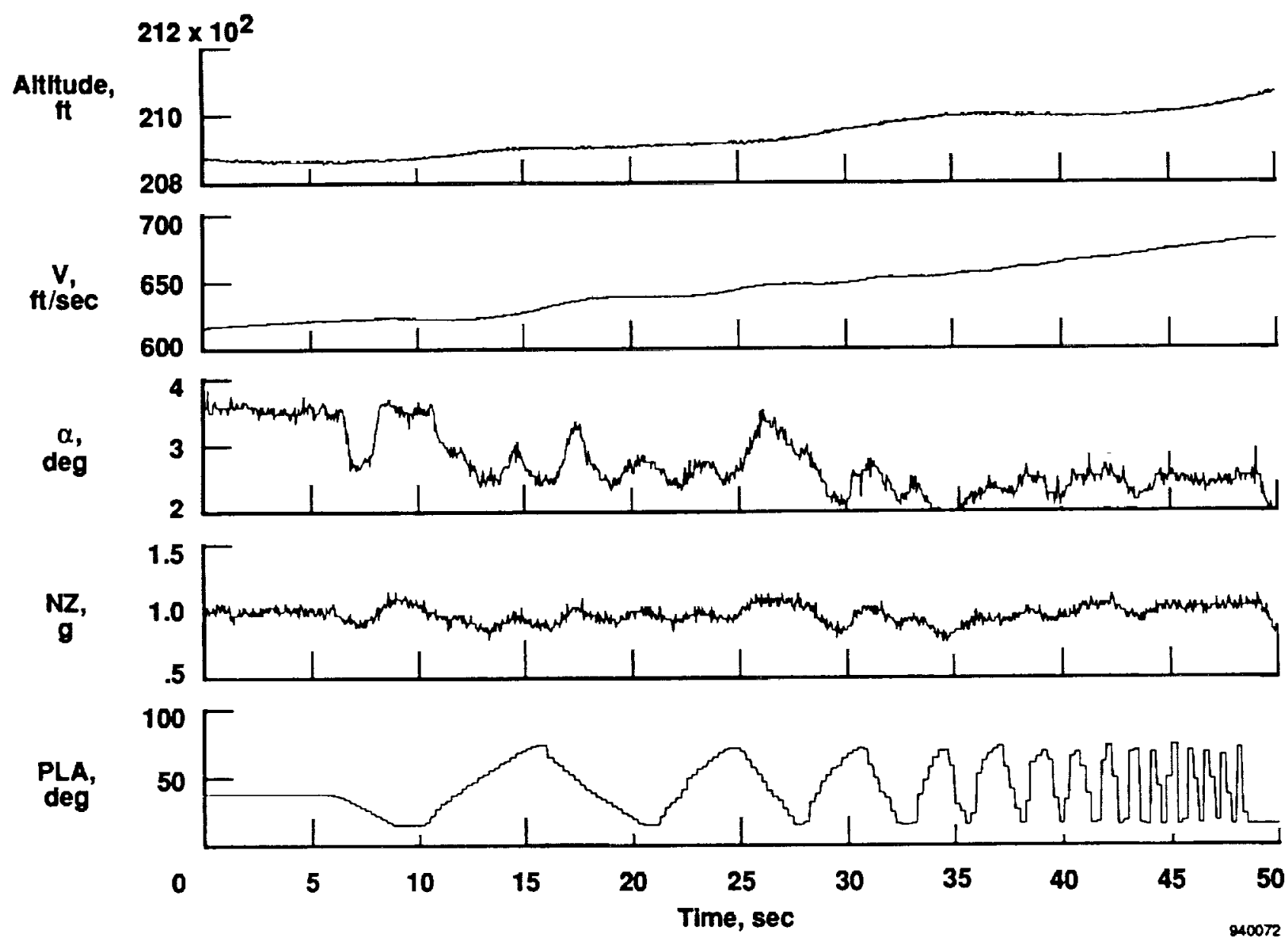

(a) Flight conditions.

Figure 9. Throttle frequency sweep maneuver for an F-15 airplane with an F100 engine. 

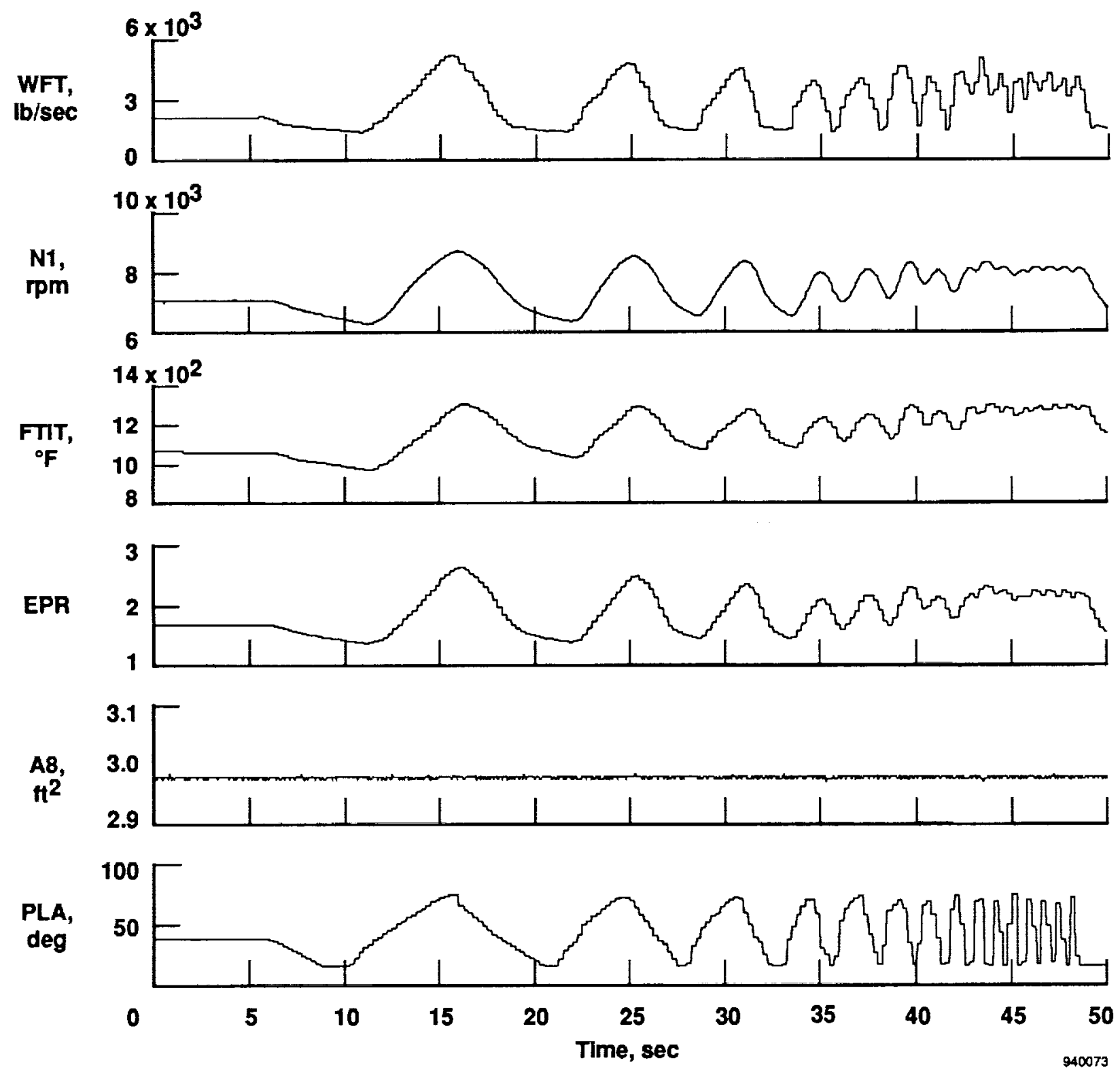

(b) Engine conditions.

Figure 9. Concluded. 

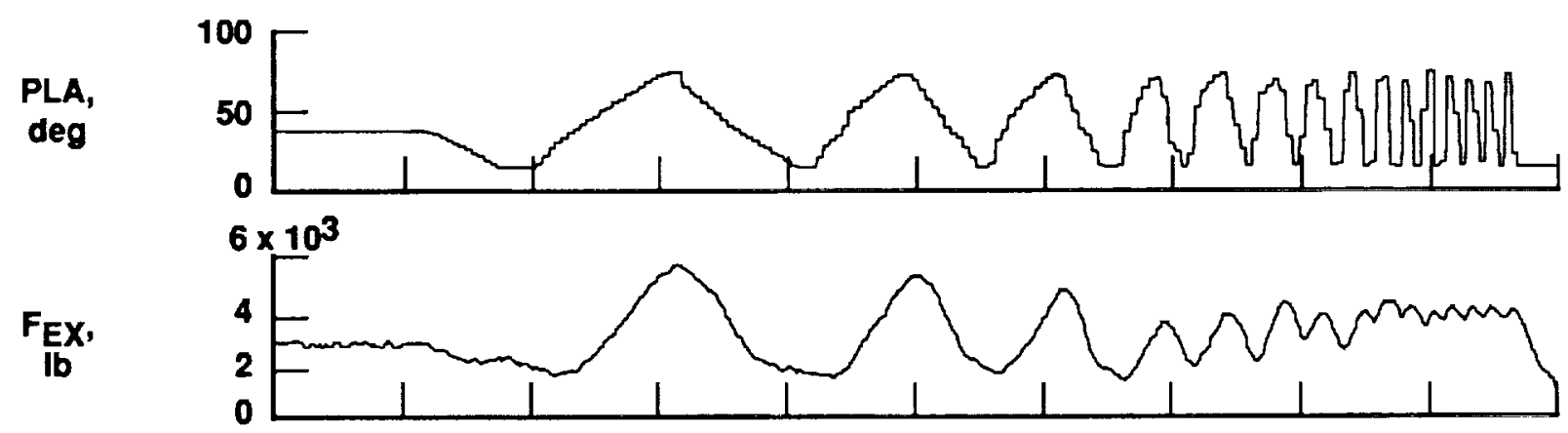

$6 \times 10^{3}$

FNPWT,

Ib
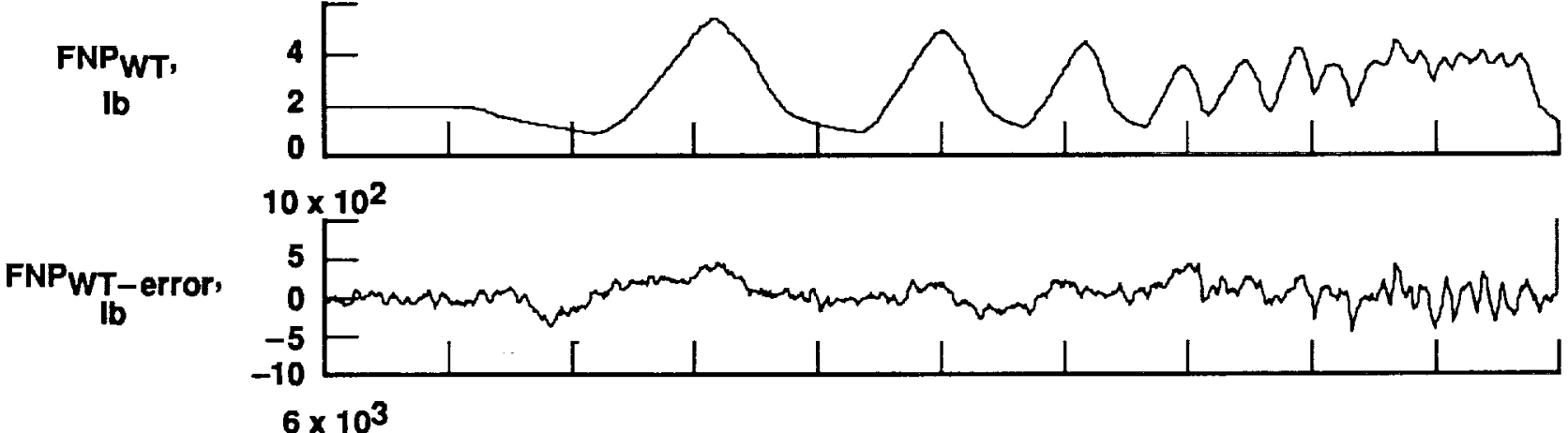

FNPAP,

Ib
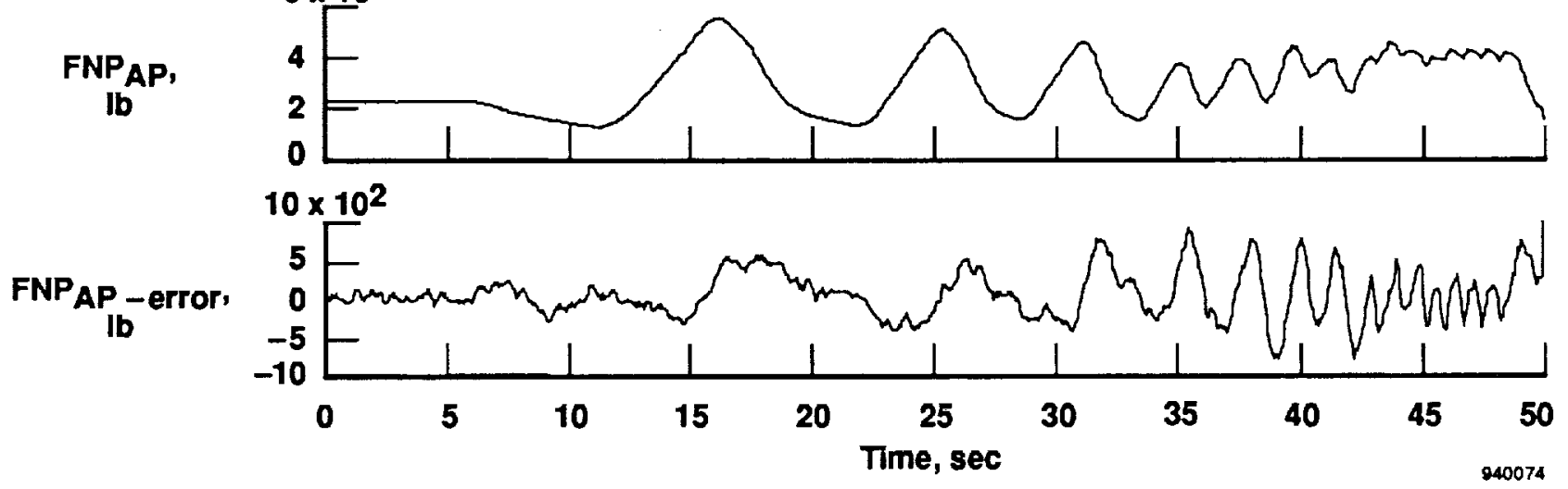

Figure 10. Error in two calculated net propulsive force values determined during a throttle frequency sweep maneuver on an F-15 airplane, equipped with an F100 engine $\left(F N P_{\text {error }}=F N P-D-F_{\alpha \alpha}\right)$. 


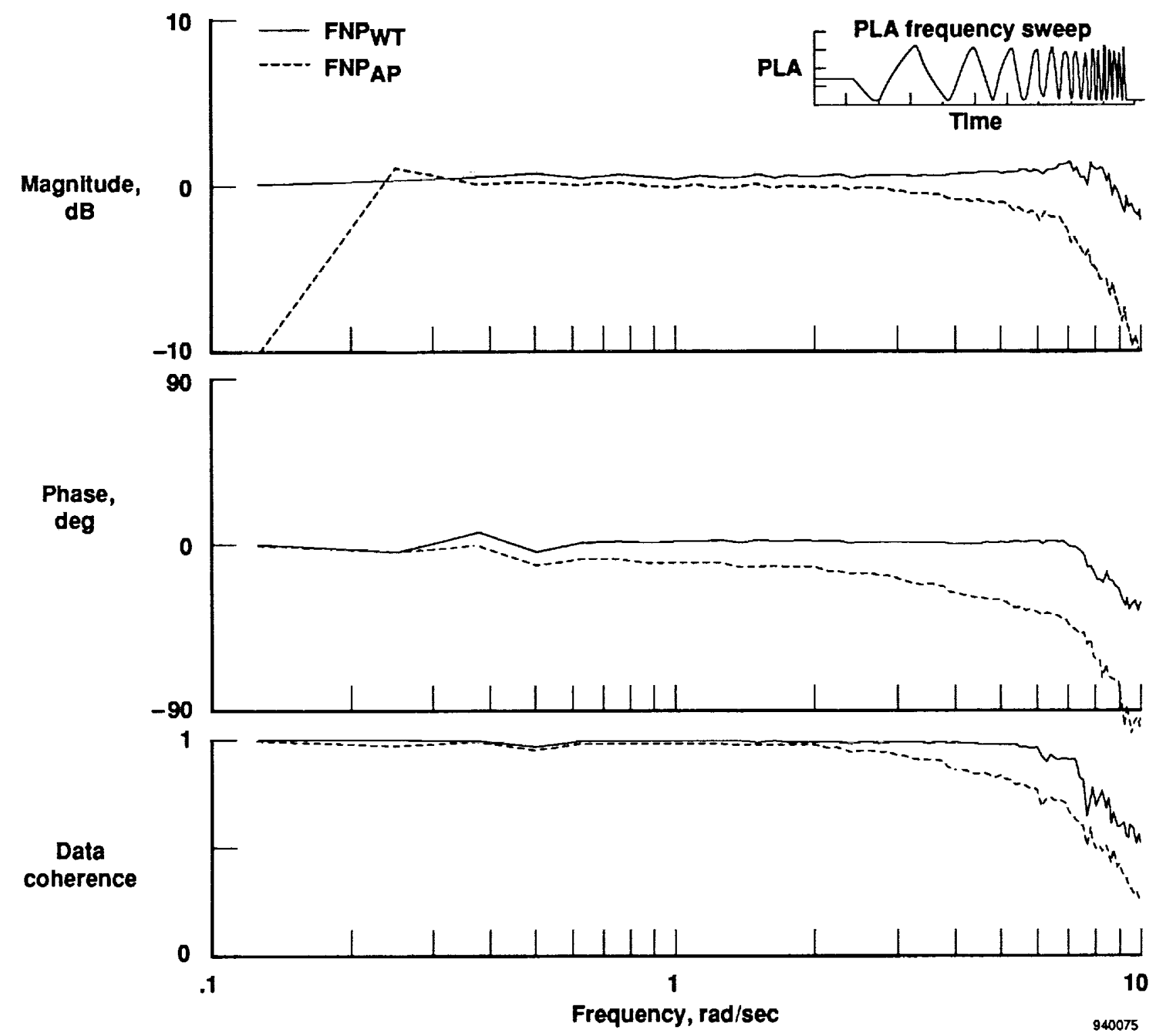

Figure 11. Frequency response of net propulsive force to excess thrust for an F-15 airplane equipped with an F100 (PW1128) engine, at 20,000 ft, and Mach 0.6. 


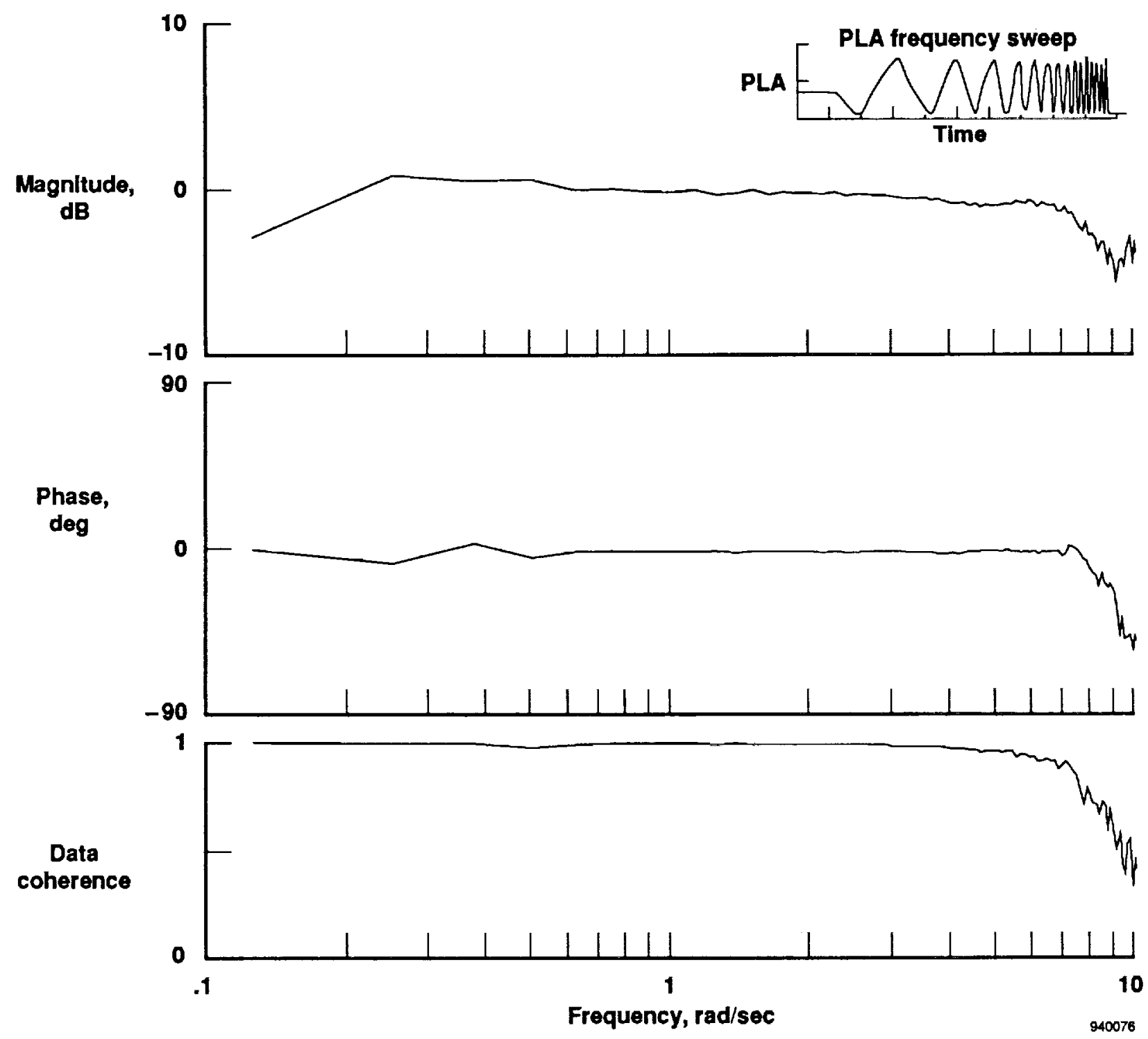

Figure 12. Frequency response of the state variable model net propulsive force to excess thrust for an F-15 airplane equipped with an F100 (PW1128) engine, at an altitude of 20,000 ft, and at Mach 0.6. 
Public reporting burden lor this collection of Information is estimaled to average 1 hour per responee, including the time lor reviewing Instructions, searching existing data sources, gathering and maintaining the date needed, and completing and reviowing the collection of intormation. Send comments regarding this burden estimate or any other aspect of this Davis Highway, Suhe 1204, Arlington, VA 22202-4302, and to the Onice of Management and Budget, Paperwork Reduction Project (0704-0188), Washington. DC 20503.

\begin{tabular}{|l|l|l|}
\hline 1. AGENCY USE ONLY (Leave blank) & $\begin{array}{l}\text { 2. REPORT DATE } \\
\text { June } 1994\end{array}$ & $\begin{array}{l}\text { 3. REPORT TYPE AND DATES COVERED } \\
\text { Technical Memorandum }\end{array}$ \\
\hline
\end{tabular}

4. TITLE AND SUBTITLE

Evaluating the Dynamic Response of In-Flight Thrust Calculation Techniques During Throttle Transients

6. AUTHOR(S)

WU 505-68

Ronald J. Ray

7. PEAFORMING ORGANIZATION NAME(S) AND ADDRESS(ES)

8. PERFORMING ORGANIZATION REPORT NUMBER

NASA Dryden Flight Research Center

P.O. Box 273

Edwards, California 93523-0273

H-1990

9. SPONSORING/MONOTORING AGENCY NAME(S) AND ADDRESS(ES)

10. SPONSORING/MONITORING AGENCY REPORT NUMBER

National Aeronautics and Space Administration

Washington, DC 20546-0001

NASA TM-4591

11. SUPPLEMENTARY NOTES

Presented as AIAA 94-2115 at the 7th Biennial Flight Test Conference, June 20-23, 1994, Colorado Springs, Colorado.

12a. DISTRIBUTION/AVAILABILITY STATEMENT 12b. DISTAIBUTION CODE

Unclassified-Unlimited

Subject Category 05

13. ABSTRACT (Maximum 200 words)

New flight test maneuvers and analysis techniques for evaluating the dynamic response of in-flight thrust models during throttle transients have been developed and validated. The approach is based on the aircraft and engine performance relationship between thrust and drag. Two flight test maneuvers, a throttle step and a throttle frequency sweep, were developed and used in the study. Graphical analysis techniques, including a frequency domain analysis method, were also developed and evaluated. They provide quantitative and qualitative results. Four thrust calculation methods were used to demonstrate and validate the test technique. Flight test applications on two high-performance aircraft confirmed the test methods as valid and accurate. These mancuvers and analysis techniques were easy to implement and use. Flight test results indicate the analysis techniques can identify the combined effects of model error and instrumentation response limitations on the calculated thrust value. The methods developed in this report provide an accurate approach for evaluating, validating, or comparing thrust calculation methods for dynamic flight applications.

14. SUBJECT TERMS

Aircraft engine simulation, Aircraft engine testing, Aircraft flight test, Dynamic thrust, Performance, Thrust, Thrust validation, Unsteady flow

\begin{tabular}{|l|l|l|}
\hline $\begin{array}{l}\text { 17. SECURITY CLASSIFICATION } \\
\text { OF REPORT } \\
\text { Unclassified }\end{array}$ & $\begin{array}{l}\text { 18. SECURITY CLASSIFICATION } \\
\text { OF THIS PAGE } \\
\text { Unclassified }\end{array}$ & $\begin{array}{l}\text { 19. SECURITY CLASSIFICATION } \\
\text { OF ABSTRACT } \\
\text { Unclassified }\end{array}$ \\
\hline
\end{tabular}

NSN 7540-01-280-5500 Available from the NASA Center for AeroSpace information, 800 Elkridge Landing Road, Linthicum Heights, MD 21090; (301)621-0390

15. NUMBER OF PAGES

29

16. PRICE CODE $\mathrm{AO} 3$

20. LIMITATION OF ABSTRACT

Unlimited

Standard Form 298 (Rev. 2-89) Standard Form 298 (Rev. Pro. 102 